\title{
Fluxo de Caixa em Risco: Diferentes Métodos de Estimação Testados no Setor Siderúrgico Brasileiro
}

\author{
Fernanda Finotti Cordeiro Perobelli* \\ Flávia Vital Januzzi*** \\ Leandro Josias Sathler Berbet*** \\ Danilo Soares de Medeiros****
}

\begin{abstract}
Resumo
O gerenciamento de riscos é assunto já estabelecido em instituições financeiras. Mais recentemente, o assunto se consolida também em empresas. Nessasem empresas. Nessas, entretanto, discussões sobre a implementação de um método capaz de informar a probabilidade de se observar um nível indesejado de fluxo de caixa numa data futura ainda são incipientes. Visando contribuir com tal discussão, este estudo propõe diferentes métodos de estimação do fluxo de caixa em risco, a partir de dados de empresas do setor siderúrgico brasileiro. São analisados dois métodos para identificação dos fatores de risco e das exposições dos componentes do fluxo a eles: coeficientes setoriais e coeficientes individuais. A partir de tal identificação, o comportamento futuro de tais fatores é simulado também de duas maneiras: a partir da série original do fator e de sua série de erros. Adicionalmente, um terceiro procedimento de fluxos futuros é testado: o bootstrap da série original dos componentes do fluxo.
\end{abstract}

Palavras-chave: Gerenciamento de riscos de mercado; instituições não-financeiras; setor siderúrgico.

Códigos JEL: G32, C15, C22, C23.

Submetido em Agosto de 2007. Aceito em Novembro de 2007. A pesquisa contou com o financiamento da FAPEMIG e do CNPq, em etapas distintas.

*FEA-UFJF. End: Rua Ivon José Curi, B23, Residencial Portal da Torre - São Pedro - 36037-467 - Juiz de Fora, MG. Tel: (32) 3237-1429. E-mail: ffinotti@labfin.com.br

**FEA-UFJF - Campus Universitário UFJF - Bairro Martelos - 36036-900 - Juiz de Fora, MG (32) 3232-7785. E-mail: flavia_januzzi@yahoo.com.br

***FEA-UFJF - Campus Universitário UFJF - Bairro Martelos - 36036-900 - Juiz de Fora, MG -

(32) 8801-3776. E-mail: leandrosathler@yahoo.com.br

****FEA-UFJF - Campus Universitário UFJF - Bairro Martelos - 36036-900 - Juiz de Fora, MG

- (32) 8823-7074. E-mail: dspmedeiros@yahoo.com.br 


\begin{abstract}
Risk management is a subject that, crisis after crisis, assumes a relevant role in the environment of non-financial companies. Despite the growing importance of the subject, debate about the introduction of a model capable of evaluating the risks to which companies are exposed is still in its infancy. Considering this gap and the importance of the theme for companies, this study proposes constructing an empirical cash flow at risk model and applying it to companies in the steel sector in Brazil. We have analyzed two methods of risk factors identification: sector components and company-level components. After such identification, simulations of risk factors future behavior were made using either the historical distribution of each risk factors and residuals of each risk factor time-series model. In addition, a third (and naïve) method was tested: bootstrap of each component of the cashflow.
\end{abstract}

Keywords: Market risks management; non-financial institutions; Brazilian steel sector.

\title{
1. Introdução
}

O gerenciamento de riscos de mercado, de crédito e operacional é um assunto que, há muito, já assumiu papel relevante e definitivo no ambiente das instituições financeiras. Mais recentemente, o assunto vem se consolidando também no âmbito de instituições não financeiras. Para essas, tal como para as instituições financeiras, torna-se fator de competitividade mensurar e gerenciar riscos capazes de afetar seu fluxo de caixa e, por conseqüência, sua capacidade financeira e solvência. Considerando a importância do assunto, o presente estudo tem por objetivo apresentar diferentes métodos para medição do risco de mercado no âmbito de empresas não-financeiras, entendidos como flutuações em variáveis próprias do negócio e econômicas capazes de afetar seu fluxo de caixa em certas datas futuras de interesse.

Dentre os benefícios advindos da implantação de sistemas de medição e gerenciamento de riscos de mercado no âmbito das instituições não financeiras, destacam-se como os mais diretos: o controle dos fluxos de caixa necessários ao cumprimento dos compromissos assumidos pela empresa, que incluem o pagamento de fornecedores, despesas operacionais e financeiras, amortização de empréstimos, investimentos programados; a redução da volatilidade desses fluxos e, conseqüentemente, da probabilidade de a empresa deixar de honrar compromissos futuros. Benefícios adicionais incluem o aumento da transparência aos investidores, a rápida assimilação de novas fontes de riscos de mercado pelos gestores e, especificamente no caso brasileiro, a adequação antecipada da empresa à regulação. A Comissão de Valores Mobiliários (CVM), por meio do Ofício Circular 01/2002 de 14 de janeiro de 2002, reforçou a necessidade de se divulgar os riscos de mercado incorridos pelas empresas em seus demonstrativos financeiros.

A despeito, entretanto, da importância crescente do assunto, discussões acerca de métodos capazes de informar a probabilidade de uma empresa observar um nível indesejado de fluxo de caixa numa data futura $t$ (fluxo de caixa em risco ou cashflow-at-risk) ainda são incipientes. É importante mencionar que medir o fluxo de caixa em risco não é apenas prever o fluxo de caixa futuro em média (estimativa 
pontual, tal como a utilizada no budget plan da empresa, em análises de valuation ou em estudos de viabilidade), mas toda a distribuição de probabilidades desse fluxo e, a partir dessa distribuição, calcular qualquer percentil ou quantil associado a tal distribuição e de interesse do pesquisador. Para fins desse trabalho, ressaltase que se definiu fluxo de caixa em risco como sendo a probabilidade do fluxo de caixa calculado pontualmente ser, na verdade, menor que zero, ou seja, fluxo de caixa em risco $=$ prob(fluxo de caixa $<0)$. De posse dessa informação, cabe à empresa adotar medidas para gerenciar e/ou se proteger contra riscos indesejados, reduzindo, com isso, tal probabilidade. ${ }^{1}$

Considerando que pesquisas sobre o tema ainda não foram largamente efetuadas, bem como a importância do mesmo para as empresas, este estudo tem como objetivo principal propor e analisar diferentes métodos de estimação do fluxo de caixa em risco, a partir da observação de dados relativos a empresas do setor siderúrgico no Brasil. São analisados dois métodos para identificação dos fatores de risco e respectivas exposições (coeficientes) dos componentes do fluxo de caixa das empresas da amostra a eles: a estimação de coeficientes setoriais (utilizando a metodologia de dados em painel) e a estimação de coeficientes individuais (utilizando a metodologia de séries temporais).

A partir da identificação dos fatores de risco pelos dois métodos e das respectivas exposições dos componentes do fluxo de caixa a eles (coeficientes), o comportamento futuro de tais fatores é simulado também de duas maneiras. Tomando-se como base a previsão do valor futuro do fator de risco, obtida a partir de um modelo de série de tempo univariado, utiliza-se: 1) a série original do fator (simulação em nível do fator de risco) para gerar a distribuição de valores futuros ao redor de tal previsão e 2) a série de erros do fator (simulação do erro do fator de risco), levantados a partir do modelo de previsão do fator, para gerar a distribuição de possíveis valores futuros ao redor da previsão.

Adicionalmente, um terceiro procedimento de geração de valores futuros de fluxo de caixa é testado: o bootstrap da série original dos componentes do fluxo de caixa, de forma a gerar a distribuição do fluxo de caixa futuro. O objetivo desse terceiro procedimento, bastante simplificado e mais próximo das abordagens top-down e backward-looking, é verificar se um método mais parcimonioso e não sujeito ao "risco de modelo" apresentaria performance melhor ou comparável a métodos estatisticamente mais sofisticados.

\footnotetext{
${ }^{1}$ A distribuição do fluxo de caixa simulada pelo método permite ainda que o usuário, caso deseje, busque o fluxo de caixa mínimo com uma certa probabilidade de ocorrência associada, invertendo a lógica originalmente proposta por este trabalho, ou seja, a partir de uma probabilidade escolhida, chega-se ao valor do fluxo de interesse (na utilização proposta, a partir do valor do fluxo de interesse, zero, busca-se a probabilidade de tal valor se verificar). Essa forma de utilização alternativa permite uma interpretação do $\mathrm{CFaR}$ bastante similar à do $\mathrm{VaR}$.
} 


\section{Referencial Teórico}

O uso de sistemas quantitativos para a medição de riscos de mercado começou a se difundir entre instituições financeiras a partir de 1994, com o lançamento, pelo JP Morgan, do documento RiskMetrics, que trazia, entre outras coisas, a metodologia de cálculo do Value-at-Risk (VaR). Dois anos se passaram até que a Securities and Exchange Comission (SEC), por pressões de órgãos reguladores, propusesse em 28 de dezembro de 1995 uma regra que exigia das companhias americanas informações quantitativas sobre riscos de mercado (Linsmeier e Pearson, 1997).

Tal regulação, aliada a um cenário de volatilidade crescente, como a proporcionada pela crise asiática em outubro de 1997 e a crise russa em agosto de 1998, serviu como incentivo para que muitas empresas americanas passassem a tentar adaptar o instrumento de controle de riscos de mercado até então utilizado apenas por instituições financeiras (VaR) às suas necessidades. Contudo, apesar de simples, intuitivo e aceito pelo mercado e pelas instituições reguladoras, tentativas mais robustas de adaptação do VaR ao ambiente corporativo foram revelando certas deficiências dessa medida em relação ao controle dos riscos de mercado a que estão expostas empresas não financeiras. Tais deficiências fizeram com que novas medidas de risco de mercado fossem ganhando espaço no âmbito dessas empresas.

Tentativas rudimentares de verificação dos impactos de oscilações nos preços de mercado sobre o fluxo de caixa são atribuídas a Vermeulen (1994), Shapiro e Titman (1999) e Bauman et alii (1999). Esses autores, entretanto, não chegaram a sugerir um modelo completo, tratando a questão apenas de forma geral.

Provavelmente, um dos trabalhos pioneiros e mais detalhados no cálculo do fluxo de caixa em risco foi o desenvolvido por Hayt e Songs (1995), que propunha uma medida de sensibilidade dos fluxos de caixa a fatores de risco. Tal medida buscava relacionar a probabilidade de a empresa atingir determinado nível de fluxo de caixa que a impedisse de honrar seus compromissos e programações de investimentos, com mudanças em preços financeiros em determinado período de tempo. Posteriormente, o trabalho de Stulz e Williamson (1997) mencionou a possibilidade de utilizar a simulação para a obtenção da distribuição esperada dos fluxos de caixa futuros.

O refinamento da medição de fluxos de caixa em risco, entretanto, só ocorreu em 1999, com a elaboração do CorporateMetrics Technical Document (Riskmetrics Group, 1999). O foco desse documento estava nos potenciais impactos de mudanças nas taxas de mercado sobre os resultados financeiros da empresa em um intervalo de tempo $t$. Entre as medidas de risco propostas e analisadas pelo CorporateMetrics estava o Cash-Flow-at-Risk (C-FaR). A metodologia empregada para o cálculo dessa medida tomava emprestados conceitos utilizados para o cálculo do VaR, adaptando-os ao ambiente corporativo, e estendia a tradicional técnica de análise de sensibilidade além de uns poucos cenários extremos, considerando um amplo conjunto de cenários simulados. Para a elaboração do método proposto, seria necessário estimar relações econométricas entre os fatores de risco e a variável de interesse (fluxo de caixa). Depois de determinadas tais relações, passar-se- 
ia à investigação do modelo capaz de descrever o comportamento dos fatores de risco. Para tal, o documento determinava não apenas que fosse construído um modelo capaz de descrever tão corretamente quanto possível a evolução dos fatores de risco, mas que ele também fosse consistente com teorias econômicas relevantes. A sugestão do documento era a utilização dos chamados Vetores Auto-Regressivos (Vector Autoregressive Model ou VARM), nos quais o valor de cada variável dependeria não só de seus valores passados, mas também dos valores passados de todas as outras variáveis do sistema, o que permitiria a previsão conjunta da média condicional dos fatores de risco.

Em 2000, o modelo desenvolvido pela consultoria National Economic Research Associates (NERA) abandonou o enfoque de séries de tempo e bottom-up (da identificação do comportamento dos fatores de risco para o fluxo de caixa em risco), predominante nos modelos anteriormente apresentados, propondo uma modelagem tipo top-down (da observação agregada do fluxo de caixa de um conjunto de empresas para o fluxo de caixa em risco de cada uma delas). A medida proposta pela NERA - denominada Comparables Cash-Flow-at-Risk (C-FaR) - seria obtida a partir da distribuição de probabilidades de fluxos de caixa observados diretamente e não mais via distribuição dos fatores de risco. Para tanto, seria necessário aglutinar os fluxos observados em um conjunto amplo e homogêneo de empresas. Depois de estimada tal distribuição, ela poderia ser usada para gerar uma série de estatísticas, tais como os percentis de 5\% e $1 \%$ da cauda inferior da distribuição. Portanto, a partir de tal distribuição seria possível responder a perguntas do tipo: "se uma empresa tem características que a classificam nesta amostra específica, qual percentual de queda máxima no fluxo de caixa tal empresa pode experimentar no horizonte $t$, com 95\% de confiabilidade?" (Stein et alii, 2001).

No mercado brasileiro, a RiskControl, em parceria com a Consultoria Tendências, desenvolveu um modelo que considerava cenários probabilísticos para os fatores de risco construídos a partir da integração de metodologias estatísticas e modelos macroeconômicos estruturais (La Roque et alii, 2003). Os modelos econômicos estruturais fazem uso da estrutura sugerida pela teoria macroeconômica na formulação de suas previsões. As relações podem ser expressas por equações, estimadas via modelos econométricos, que se articulam. Assim, é possível captar as interações relevantes entre as variáveis de interesse. Diferentemente do VARM, no entanto, esses modelos assumem a existência de variáveis independentes exógenas nas equações, estimadas por meio de dados históricos e regressões econométricas, e variáveis dependentes endógenas, que estão em função das exógenas estimadas. Para inserir incerteza no modelo, a RiskControl/Tendências propunha que as séries de variáveis exógenas fossem decompostas em tendência e resíduo. Estimadas as tendências das séries, a volatilidade condicional de cada uma delas seria estimada usando-se as diferenças entre os valores assumidos pela série e sua tendência (resíduo). Entendida a dinâmica da volatilidade individual de cada uma das variáveis exógenas, seria preciso verificar a dinâmica de covariância entre elas. De acordo com a RiskControl/Tendências, estas seriam 
melhor estimadas pela tendência das séries e não pelos resíduos. Estimadas as volatilidades e as covariâncias, a simulação das trajetórias conjuntas assumidas pelas variáveis exógenas seria obtida via Simulação de Monte Carlo. Quanto às endógenas, se a incerteza em relação às exógenas já estivesse corretamente modelada, bastaria substituir os valores simulados para as exógenas nas equações das endógenas.

Também Varanda Neto (2004) utilizou o CFaR como ferramenta de mensuração de risco para um estudo de caso da empresa geradora de energia AES Tietê S/A. As variáveis que impactaram a receita, nesse estudo, foram consideradas aleatórias e devidamente simuladas por Monte Carlo (a partir de modelo de geração de valores futuros simplificado, do tipo Movimento Browniano Geométrico). Os diferentes cenários gerados para as variáveis macroeconômicas resultaram em diferentes cenários possíveis para o fluxo de caixa estudado. O autor simulou ainda o EaR (Earnings-at-Risk) da empresa.

Por fim, Perobelli e Securato (2005) desenvolveram um modelo para medição do fluxo de caixa em risco de empresas distribuidoras de energia elétrica que combinou a metodologia de dados em painel (para identificação dos fatores de risco relevantes e das exposições das empresas a eles) com a técnica de vetores autoregressivos para estimação do comportamento futuro desses fatores de risco sugerida pelo CorporateMetrics.

\section{Modelo Teórico para Cashflow-at-Risk}

Repassados os principais estudos sobre o assunto, o objetivo dessa seção é apresentar sumariamente o modelo teórico utilizado pela maioria dos estudos descritos para a mensuração do fluxo de caixa em risco das empresas, aqui entendido como a probabilidade de a empresa não dispor de recursos gerados pelas operações no período suficientes para honrar seus compromissos em determinadas datas futuras ${ }^{2}$ (vértices do fluxo) ou, estatisticamente, como o percentil associado à estatística de ordem zero da distribuição do fluxo de caixa da empresa.

Metodologicamente, para a construção do modelo devem ser considerados os pontos seguintes:

(1) Definição das variáveis de estudo, subdividindo-as em variáveis dependentes (contas componentes do fluxo de caixa) e candidatas a variáveis independentes (fatores de risco macroeconômicos - FRM - e próprios do negócio FRP);

(2) Definição dos vértices temporais em que tais variáveis serão observadas e o horizonte temporal de previsão (número de passos à frente - t);

\footnotetext{
${ }^{2}$ É importante mencionar que, para uma análise mais completa da liquidez da empresa, é imperativo que o saldo inicial das disponibilidades da empresa (Caixa e Aplicações Financeiras) seja também considerado na análise. Os autores agradecem os comentários a esse respeito feitos por um dos pareceristas deste artigo.
} 
(3) Identificação dos fatores de risco relevantes (entre macroeconômicos e próprios da empresa) via estimação da relação estatística existente entre as variáveis dependentes e as candidatas a variáveis independentes;

(4) Sugestão de um tratamento para o gerenciamento dos fatores de risco próprios e estimação, via modelagem econométrica, do comportamento médio esperado dos fatores de risco macroeconômicos, bem como de sua matriz de variância-covariância;

(5) Simulação de cenários para os fatores de risco macroeconômicos no horizonte de previsão, tomando o cuidado de manter a estrutura de variânciacovariância observada entre as séries históricas desses fatores;

(6) Inserção dos valores previstos para os fatores de risco em cada cenário na equação que relaciona o comportamento de tais fatores ao comportamento das variáveis dependentes (contas componentes do fluxo de caixa);

(7) Montagem da distribuição simulada das variáveis dependentes (contas componentes do fluxo de caixa) e determinação da estatística de interesse da distribuição do fluxo de caixa.

\subsection{Variáveis do modelo, seus vértices de medição e seu horizonte de pre- visão}

Para a formulação do modelo, é preciso definir as variáveis dependentes, assim como selecionar candidatas a variáveis independentes - fatores de risco macroeconômicos e próprios do negócio, capazes de alterar o comportamento das variáveis dependentes ao longo do tempo.

Considerando-se que o modelo baseia-se na mensuração do fluxo de caixa em risco, a variável de interesse geralmente é o fluxo de caixa operacional da empresa (FC), observado em certas datas de pagamento futuras, ou vértices do fluxo. Tal variável é calculada a partir de cada um de seus componentes (receitas, custos e despesas), consideradas variáveis dependentes. A Equação 1 evidencia a determinação do fluxo de caixa operacional a partir de seus componentes:

$$
F C_{t}=f\left(Y_{1}, \ldots, Y_{m}\right)
$$

onde:

$F C$ é o fluxo de caixa operacional;

$f$ é um função determinística; e

$Y_{1}, \ldots, Y_{m}$ variáveis contábeis.

Dessa forma, pode ser feita contemporaneamente as simulações das contas componentes do fluxo de caixa e do próprio fluxo de caixa, conforme detalhado na seção 4, a seguir. As candidatas a variáveis independentes são fatores capazes de provocar oscilações no fluxo de caixa operacional das empresas, ou fatores de 
risco. Tais fatores de risco podem ser macroeconômicos (nível de taxas de juros, câmbio, inflação, risco-país, produção nacional) - capazes de afetar, em maior ou menor grau, todas as empresas da economia - e fatores de risco próprios do negócio (nível de endividamento, mercado atendido, investimentos programados).

A consideração no modelo de características próprias da empresa como candidatas a fatores de risco tem como objetivo dar-lhe flexibilidade. Enquanto as oscilações nos fatores de risco macroeconômicos não podem ser determinadas $a$ priori pela empresa, mas apenas estimadas e hedgeadas caso seus potenciais efeitos sobre o fluxo de caixa assim o justifiquem, a identificação prévia de fatores de risco gerenciáveis permite à empresa verificar, por exemplo, quais seriam os impactos em seu fluxo de caixa em determinada data se, além de choques esperados nos fatores de risco macroeconômicos, ela também decidisse alterar sua estrutura operacional e financeira via aumento de market share, novos investimentos, aumento de endividamento, substituição de dívida em moeda estrangeira por dívida em moeda nacional, etc. A Equação 2 traz a especificação de cada componente do fluxo de caixa em função dos fatores de risco:

$$
Y_{s t}=b_{s 0}+\sum_{j=1}^{k} b_{s j} F R P_{s j t}+\sum_{j=k+1}^{r} b_{s j} F R M_{s j t}+e_{s t}
$$

para $s=1, \ldots, m$ (componentes do fluxo de caixa);

$j=1, \ldots, r$ (fatores de risco próprio e macroeconômicos relevantes);

$t=1, \ldots, T$ (número de passos à frente).

Com relação aos vértices de medição, datas em que se observam as variáveis dependentes e independentes, podem ser usados vértices diários, semanais, mensais ou trimestrais. Dessa forma, tal como na estimação do VaR, em que se assume que pagamentos e recebimentos não ocorram todos os dias, mas apenas em determinadas datas, o fluxo de caixa da empresa pode ser observado a cada trimestre, vértice que concentra (hipoteticamente) todos os pagamentos e recebimentos.

Ressalte-se que a divulgação pelas empresas de dados contábeis em base trimestral geralmente é a responsável por tal escolha. Obviamente, tal restrição é relevante apenas ao pesquisador externo. Caso o estudo esteja sendo conduzido com informações privadas, tais vértices podem ser diários, semanais ou mensais, ou obedecer às datas constantes no budget plan elaborado pela empresa.

Da mesma forma, o horizonte de previsão - número de passos à frente em que os fluxos são observados - fica a critério do pesquisador e da empresa interessada. Ressalte-se, porém, que, quanto mais longo for o prazo, menor a confiabilidade das estatísticas geradas. Nada impede, entretanto, que as estimativas geradas sejam periodicamente revistas, de modo a se atualizar constantemente a estimação pela consideração de novas observações passadas. 


\subsection{Identificação dos fatores de risco macroeconômicos e próprios relevantes}

Enquanto a metodologia do VaR (método do qual se originam as primeiras tentativas de medição do fluxo de caixa em risco) exige o mapeamento do portfólio e a identificação de um número reduzido de fatores de riscos primitivos que repliquem, de forma linear e determinística, as oscilações no valor de mercado dos ativos originais, identidades semelhantes não são facilmente obtidas para o cálculo do fluxo de caixa em risco.

Apesar dos modelos de fluxo de caixa em risco apresentados enfatizarem a necessidade de se identificar as exposições aos fatores de riscos mais relevantes da empresa, oscilações nas receitas apuradas, ou nos custos incorridos, não podem ser normalmente expressos, de forma determinística, em termos desses fatores. No caso do fluxo de caixa em risco, o mais próximo da replicação determinística utilizada pelo VaR possível é via estimação de um modelo estatístico que relacione oscilações nas contas do fluxo a oscilações nos fatores de risco. Portanto, o próximo passo é estimar equações que relacionem as oscilações nos componentes do fluxo de caixa operacional da empresa (variáveis dependentes) a oscilações nos fatores de risco (variáveis independentes).

Para a estimação dessas equações, este estudo propõe dois procedimentos:

(1) estimação de coeficientes setoriais (utilizando a metodologia de dados em painel) e;

(2) estimação de coeficientes individuais (utilizando a metodologia de séries temporais).

Sobre o primeiro método, considerando que, no Brasil, as empresas apenas divulgam informações contábeis, necessárias ao cálculo do fluxo de caixa, em base trimestral, tal procedimento visa aumentar o volume de dados na estimação, principalmente para o analista externo à empresa, além de também permitir a consideração de características próprias da empresa, que a diferenciem das demais, na estimação de seu fluxo de caixa em risco. Porem risco. Por outro lado, a estimação dos fatores de risco via dados em painel possui a desvantagem de gerar coeficientes comuns a todas as empresas pertencentes à amostra. Assim, caso as empresas sejam influenciadas por fatores de risco díspares, a estimação via painel ficará comprometida. De forma a testar essa possibilidade, a pesquisa também propõe a determinação dos fatores de risco de uma única empresa, com estimação em série de tempo. Para tanto, foram testados os seguintes métodos: Amortecimento Exponencial, Box \& Jenkins e Regressão Dinâmica. Já no método de dados em painel, foram testadas as especificações de efeitos aleatórios e fixos, além de ter sido empregado também o método de GMM-Sys ou Painel Dinâmico sempre que a variável dependente defasada se fazia relevante, seguindo modelo proposto por Blundell e Bond (1998). 


\subsection{Tratamento dos fatores de risco próprios e estimação do comportamento médio esperado dos fatores de risco macroeconômicos}

Realizada a estimação via dados em painel e em séries de tempo e identificados os fatores de risco relevantes entre os candidatos pré-selecionados, o próximo passo do modelo é estimar o comportamento médio esperado desses fatores ao longo do tempo. Ressalte-se que, por sua característica mais estável, os fatores de risco próprios da empresa não têm seu comportamento futuro projetado neste modelo. Espera-se que, numa situação real, a empresa tenha ciência dos valores futuros a serem assumidos por tais fatores via planejamento periódico: nível de investimento em capital de giro necessário, ${ }^{3}$ nível de endividamento, contratação ou amortização de dívidas em moeda nacional ou estrangeira, novos investimentos, venda de ativos, novos aportes de capital e transferência de recursos para os acionistas. Na modelagem, os valores assumidos pelos fatores de risco próprios são desconsiderados. Nada impede, entretanto, que, no caso de uma pesquisa interna, realizada com informações privadas, tais valores esperados sejam fornecidos pela empresa, de acordo com sua estratégia de atuação.

Portanto, o foco neste passo está na estimação dos valores futuros dos fatores de risco macroeconômicos. Neste trabalho, a estimação é feita via métodos clássicos de série de tempo: Amortecimento Exponencial, Box \& Jenkins e Regressão Dinâmica, estimados no software ForecastPro, de acordo com a Equação 3 abaixo:

$$
F R M_{j t}=g(t)+e_{j t}
$$

onde $g(t)$ é uma função univariada do tempo que representa estimação do $F R M$ por um modelo autoprojetivo do FPW.

\subsection{Simulação de cenários para os fatores de risco macroeconômicos}

Escolhido e estimado o modelo para previsão dos valores médios dos fatores de risco macroeconômicos, a simulação da distribuição de probabilidade para cada fator será realizada, neste trabalho, por Monte Carlo, a partir do sorteio de n choques aleatórios, a serem filtrados via fatoração de Cholesky, conforme Hamilton (1994) e Riskmetric Group (1999). Após filtrados, os valores simulados para os fatores de risco são inseridos na equação das variáveis dependentes e dessas na equação do fluxo de caixa operacional, contemporaneamente, dando origem às

${ }^{3}$ É importante mencionar que o nível de investimento em capital de giro varia conforme o nível de atividade da empresa e suas políticas de prazo (de estoques, de recebimento e de pagamentos). Uma vez calculado o nível atual de investimento em giro, este pode ser segmentado em fixo e variável. Enquanto o segmento fixo varia em degraus, conforme mudanças no nível de caixa mínimo pretendido, no número de empregados, nos tributos, etc., o segmento variável oscila conforme as receitas e custos previstos, sendo interessante, portanto, internalizá-lo no modelo. Novamente os autores agradecem os comentários de um dos pareceristas a esse respeito. 
distribuições dessas variáveis. O detalhamento dessa simulação pode ser observado no Apêndice A.

Nesta pesquisa, o procedimento de simulação será realizado de duas maneiras. Tomando-se como base a previsão do valor futuro do fator de risco, obtida a partir de um modelo de série de tempo univariado, utiliza-se:

(1) a série original do fator (simulação em nível do fator de risco) para gerar a distribuição de valores futuros ao redor de tal previsão e

(2) a série de erros do fator (simulação do erro do fator de risco), levantados a partir do modelo de previsão do fator, para gerar a distribuição de possíveis valores futuros ao redor da previsão.

Adicionalmente, um terceiro procedimento de geração de valores futuros de fluxo de caixa é testado: o bootstrap da série original dos componentes do fluxo de caixa, de forma a gerar a distribuição do fluxo de caixa em risco futuro.

A Figura 1 apresenta esquematicamente os passos a serem dados para estimação do fluxo de caixa em risco. Explorados todos os passos do modelo teórico, passa-se à proposta dos métodos empíricos de construção do modelo.

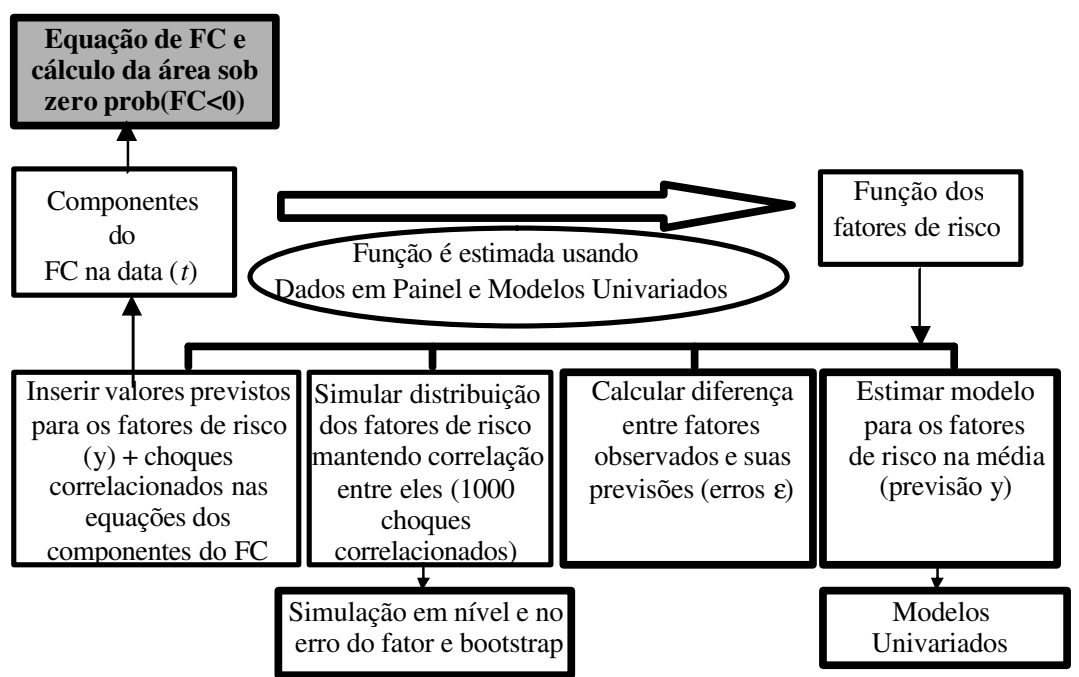

Fonte: Elaboração própria

Figura 1

Esquema de cálculo do fluxo de caixa em risco 


\section{Métodos Empíricos para Cashflow-at-Risk}

Exposta a metodologia teórica para a estimação do fluxo de caixa em risco, esta seção destina-se à proposta empírica dos métodos de estimação propostos a partir de dados de empresas pertencentes ao setor de siderurgia brasileiro.

\subsection{Amostra de trabalho e dados coletados}

A aplicação empírica considera como variáveis dependentes componentes do fluxo de caixa operacional (FC) das empresas, observados três (3) períodos à frente $(t=3)$, em vértices trimestrais. Para tanto, trabalha-se com os dados disponíveis do $1^{\circ}$ trimestre de 1995 até o $4^{\circ}$ trimestre de 2005 , reservando-se os do $1^{\circ}, 2^{\circ}$ e $3^{\circ}$ trimestres de 2006 para procedimentos de backtesting (comparação fora da amostra de estimação).

Inicialmente foram selecionadas 9 empresas do setor siderúrgico (ACESITA, Aços Altona, Aços Villares, Belgo Mineira, Gerdau, USIMINAS, COSIPA, CST, CSN) para compor a amostra de trabalho. Dessas, após análise das particularidades de cada empresa e algumas mudanças ocorridas com algumas deles (incorporações e mudanças de objetivos sociais ocorridas em Belgo Mineira, Gerdau e COSIPA), foram selecionadas cinco (05) empresas (ACESITA, Aços Villares, USIMINAS, CST, CSN).

A partir da análise dos demonstrativos contábeis dessas empresas, extraiu-se, em base trimestral, desde o $1^{\circ}$ trimestre de 1995 (ou desde quando disponível), as seguintes informações:

I. Demonstração do Resultado do Exercício (DRE):

a) receita líquida trimestral (em $R \$)-R E C L$;

b) custo dos produtos vendidos (em R \$) - CMV;

c) despesas operacionais (em R \$) - DESPOP;

d) despesas financeiras líquidas (em R\$) - DESPFIN;

e) receitas financeiras líquidas (em R\$) - RECFIN;

f) resultado financeiro $(d+e)(\mathrm{em} \mathrm{R} \$)-\mathrm{RESFIN}$;

II. Relatório Anual ou Comentário de Desempenho do Trimestre

g) vendas para o mercado externo (em \% das vendas totais) - ME;

h) estoque de dívida em moeda estrangeira (em R \$) - DIVNAC;

i) estoque de dívida em moeda nacional (em R\$) - DIVEST.

Ressalta-se que as informações acima referem-se às empresas controladoras, expressas em moeda do período, sem qualquer indexação ou correção monetária. Além das informações específicas das empresas, levantou-se, a partir de diversas bases de dados, as seguintes informações macroeconômicas: 
j) Produto Interno Bruto

(variação no trimestre) - PIBBRASIL

Fonte: Banco Central do Brasil

k) Produto Interno Bruto da Construção Civil

(variação no trimestre) - PIBCONSTCIVIL

Fonte: IPEA

1) Produto Interno Bruto - Industrial

(variação no trimestre) - PIBIND

Fonte: IPEA

m) Indicador da Produção Industrial

(variação no trimestre) - PRODIND

Fonte: IBGE

n) Exportação Agregada

(variação no trimestre) - EXPAGREG

Fonte: IPEA

o) Índice Geral de Preços Amplo

(taxa acumulada no trimestre) - IPCA

Fonte: IBGE

p) Índice Nacional de Preços da Construção Civil

(taxa acumulada no trimestre) - INCC

Fonte: FGV

q) Taxa de Juros de Longo Prazo

(taxa acumulada no trimestre) - TJLP

Fonte: Economática

r) Taxa Básica de Juros Brasileira

(taxa acumulada no trimestre) - SELIC

Fonte: Economática

s) Variação da Taxa de Câmbio R \$/US\$

(variação no trimestre) - PTAX

Fonte: Economática

t) Variação da Taxa de Câmbio $\mathrm{R} \$ /$ Euro

(variação no trimestre) - EURO

Fonte: Economática 
u) PU Título da Dívida Externa Brasileira

(variação no PU do trimestre) - CBOND

Fonte: Economática

v) Consumer Price Index

(taxa acumulada no trimestre) - CPIUSA

Fonte: Economática

x) Taxa de Juros Americana

(taxa acumulada no ano, por trimestre) -TNOTEAA

Fonte: Economática

y) Salário Real e Nominal na Indústria

(variação no trimestre) - SALARIONOM/SALARIOREAL

Fonte: IBGE

z) Nível de Emprego na Indústria

(variação no trimestre) - EMPREGO

Fonte: IBGE

Algumas das informações retrocitadas foram utilizadas na construção da variável de interesse do modelo (fluxo de caixa operacional), conforme detalhado no item 4.2. As demais foram testadas como variáveis independentes, portanto, passíveis de determinar oscilações nos componentes do fluxo de caixa operacional das empresas.

\subsection{Determinação do fluxo de caixa de cada empresa $i$, na data $t$}

De forma a viabilizar a obtenção do fluxo de caixa contábil para todas as empresas do setor siderúrgico constantes da amostra, nos 44 trimestres considerados (entre 1T/95 e 4T/05), optou-se por adotar o modelo de Geração de Caixa Bruta, onde fluxo de caixa é dado por receita líquida, menos custo do produto vendido, menos despesas operacionais, mais resultado financeiro líquido, conforme Equação 4:

$$
F C_{i, t}=R E C L_{i, t}-C M V_{i, t}-D_{E S P O P}, t+R E S F I N_{i, t}
$$

A variável assim criada, para cada empresa $i$, em cada data $t$, é denominada neste trabalho Fluxo de Caixa Operacional (FC). Em relação aos vértices do fluxo (datas de interesse), destaca-se que a existência de dados em base trimestral, menor desagregação possível de informações públicas, foi responsável pela escolha dos vértices trimestrais de pagamento nessa aplicação. Portanto, os vértices do fluxo foram sempre março, julho, setembro e dezembro de cada ano. 


\subsection{Escolha dos candidatos a fatores de risco}

A escolha dos candidatos a variáveis independentes limitou-se pela disponibilidade de dados existentes e pela necessidade de se chegar a resultados parcimoniosos, que permitissem a estimação do comportamento futuro dos fatores de risco, bem como das inter-relações entre eles. Assim, a opção foi considerar as seguintes variáveis como explicativas:

a) ME;

b) DIVEST e DIVNAC;

c) PIBBRASIL, PIBCONSTCIVIL, PIBIND, PRODIND, EXPAGREG

d) IPCA e INCC

e) TJLP e SELIC

f) PTAX e EURO

g) CBOND

h) CPIUSA e TNOTEAA

i) SALARIOREAL E SALARIONOM

j) EMPREGO

1) HEDGEJUROS

m) HEDGECAMBIO

As variáveis PIBBRASIL, PIBCONSTCIVIL, PIBIND, PRODIND, EXPAGREG e EMPREGO foram incluídas como proxies para nível de atividade na economia; IPCA e INCC como proxy para inflação; TJLP e SELIC como proxies para taxas de juros, que limitam o consumo das famílias, ao mesmo tempo em que indexam uma parte do endividamento das empresas; PTAX e EURO para câmbio, CBOND, CPIUSA e TNOTEAA como proxies para atração de capital estrangeiro; SALARIOREAL, SALARIONOM e PRECOALG foram incluídos por representarem importantes custos para as empresas. Adicionalmente, foram criadas duas variáveis dummy para representar o hedge de juros e de câmbio (HEDGEJUROS e HEDGECAMBIO), que assumiram valor 1 quando a empresa declarou possuir algum instrumento de proteção de seus fluxos, além de dummies de trimestre $\left(t d_{1}\right.$, $t d_{2}, t d_{3}$ e $\left.t d_{4}\right)$. 
É importante ressaltar que a escolha, a priori, do conjunto de potenciais variáveis explicativas não obedeceu a nenhum critério estatístico, mas, ao contrário, foi empreendida tomando-se por base apenas o estudo do setor. Obviamente, ao escolher um conjunto tão restrito de variáveis, deixa-se de fora um vasto campo de pesquisa. Nesse sentido, é importante esclarecer que algumas outras variáveis adicionais necessitariam ser incluídas (custo da matéria-prima, preços dos produtos produzidos, estatísticas de comércio exterior), e, se não o foram, foi devido unicamente a restrições nas bases de dados consultadas. Entretanto, conforme já mencionado, caso a pesquisa seja realizada com informações disponibilizadas pela própria empresa, espera-se que o acesso às bases de dados relevantes não sofra tal restrição.

\subsection{Identificação dos fatores de risco relevantes: estimação em painel}

Para a estimação da equação determinante dos fatores de risco do fluxo de caixa, adotou-se como primeiro procedimento estimar, via painel, os fatores de risco de cada componente do FC separadamente, quais sejam: Receita Líquida (RECL), Custo da Mercadoria Vendida (CMV), Despesas Operacionais (DESPOP), Resultado Financeiro (RESFIN). Ao final da estimação, as contas componentes do FC foram novamente somadas, de modo a restaurar a variável de interesse.

Considerando que a aplicação realizada utilizou unicamente informações públicas (de fora da empresa) e que as empresas apenas divulgam informações contábeis em base trimestral, a opção pela estimação em painel aumentou consideravelmente o volume de informações disponíveis. Caso a opção fosse por trabalhar com uma única empresa observada desde 1995, haveria 44 trimestres para estimação e 3 para backtesting. Ao trabalhar com 5 empresas foram 220 dados para estimação e 15 para backtesting. A seguir, apresentam-se as figuras da estimação via dados em painel, realizada no software STATA 8.0. As variáveis explicativas em cada modelo, bem como seus coeficientes, podem ser observados nas Figuras abaixo ("Painel Nível").

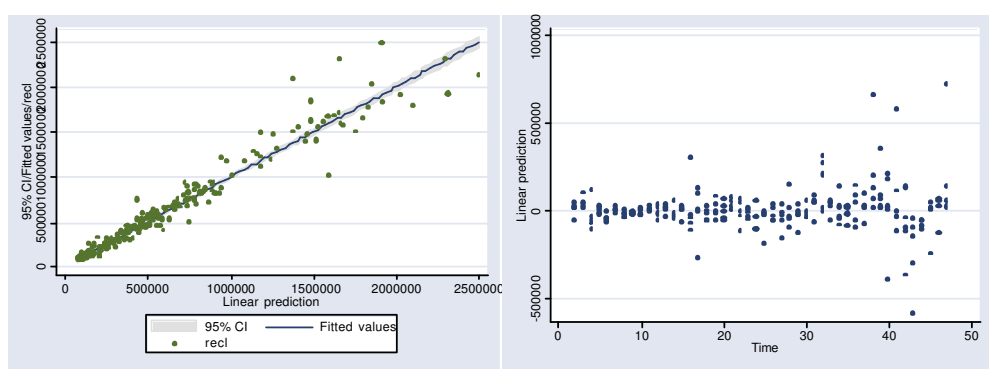

Figura 2

Ajustamento "receitas líquidas" (PAINEL) 

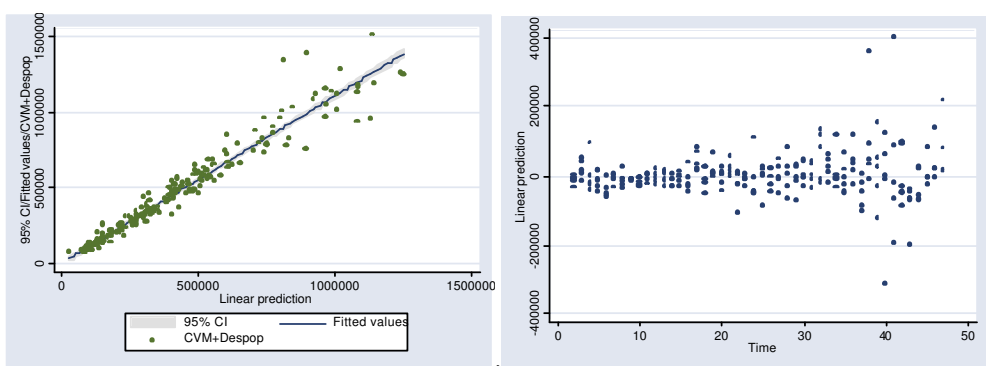

Figura 3

Ajustamento "custo das mercadorias vendidas" (PAINEL)

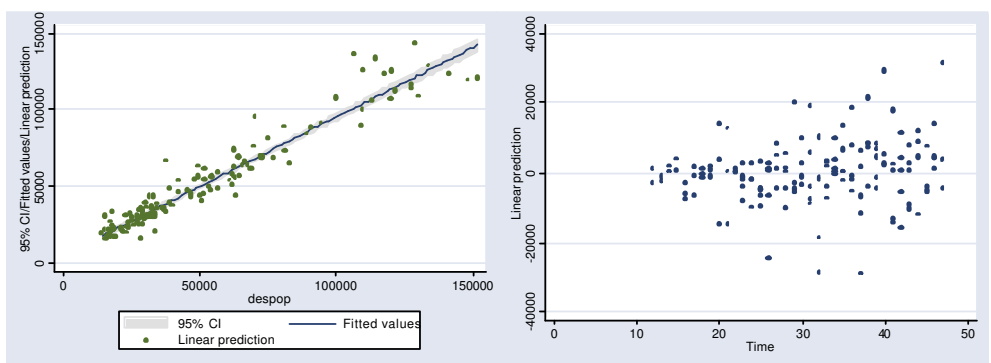

Figura 4

Ajustamento "despesas operacionais" (PAINEL)
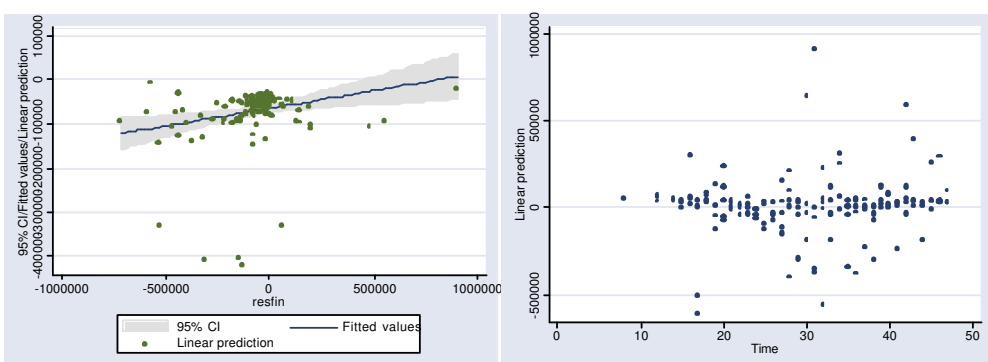

Figura 5

Ajustamento "resultados financeiro" (PAINEL) 


\subsection{Identificação dos fatores de risco relevantes: estimação via séries de tempo}

Para identificação dos fatores de risco via modelos de séries de tempo, os procedimentos utilizados foram os mesmos descritos na estimação via dados em painel, exceto pela diferença evidente de nessa estimação ter-se considerado apenas os dados relativos a cada empresa. Dessa maneira, houve 44 trimestres para estimação e 3 para backtesting em cada estimação. Neste artigo, por limitação de espaço, os resultados serão reportados apenas para a empresa USIMINAS. Essa empresa foi escolhida por ter apresentado os melhores resultados na estimação em painel, passando, portanto, a ser utilizada como base de comparação para os três métodos analisados. ${ }^{4}$ A seguir, apresentam-se os gráficos da estimação via séries de tempo, realizada no software FPW As variáveis explicativas para cada conta, bem como seus coeficientes, também podem ser observados nas Figuras abaixo ("Individual Nível”).
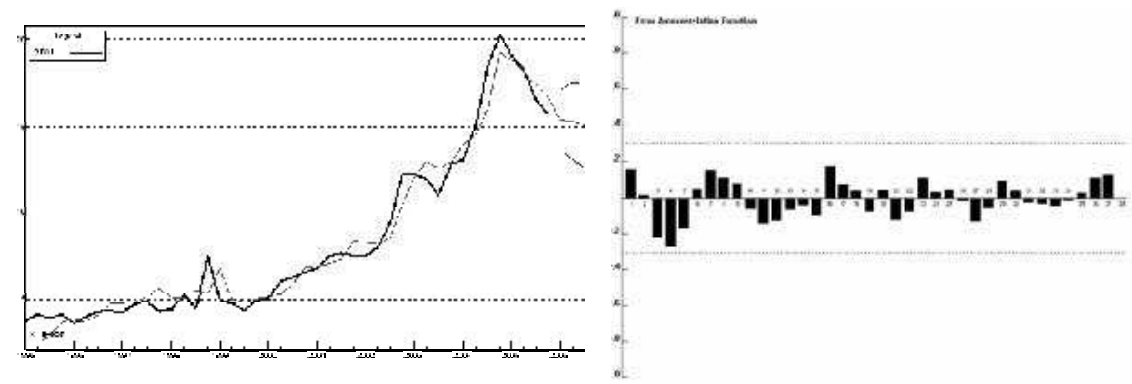

Fonte: Elaboração própria a partir do FPW

\section{Figura 6}

Ajustamento "Receita Líquida" (INDIVIDUAL)

\footnotetext{
${ }^{4}$ Os resultados relativos às demais empresas da amostra podem ser disponibilizados mediante solicitação. Ressalta-se que os resultados apresentados a seguir são aplicáveis apenas à empresa em questão, não sendo passíveis de serem extrapolados às demais empresas da amostra. Ou seja, não há o melhor método, mas sim o melhor método para cada situação (empresa analisada).
} 


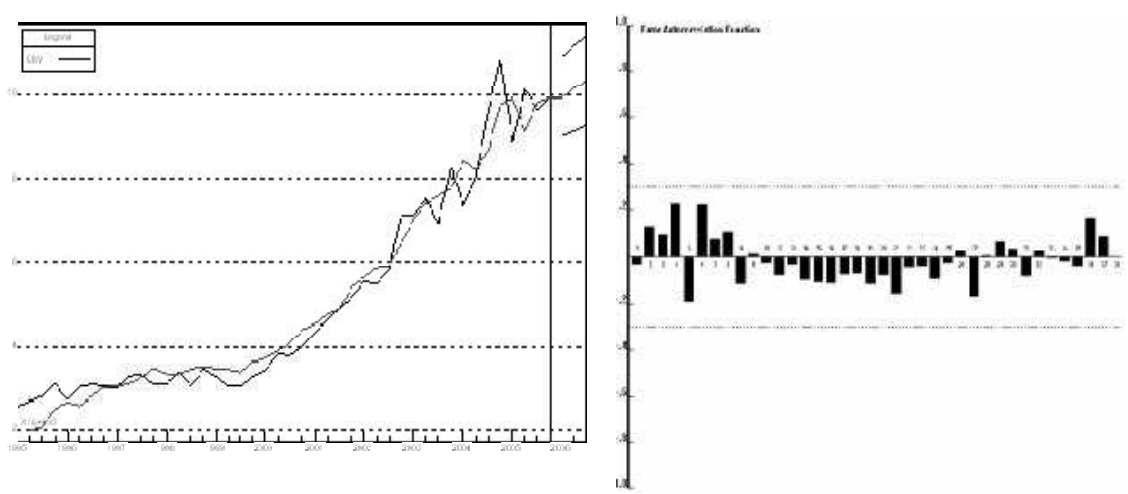

Fonte: Elaboração própria a partir do FPW

Figura 7

Ajustamento "Custo das Mercadorias Vendidas" (INDIVIDUAL)

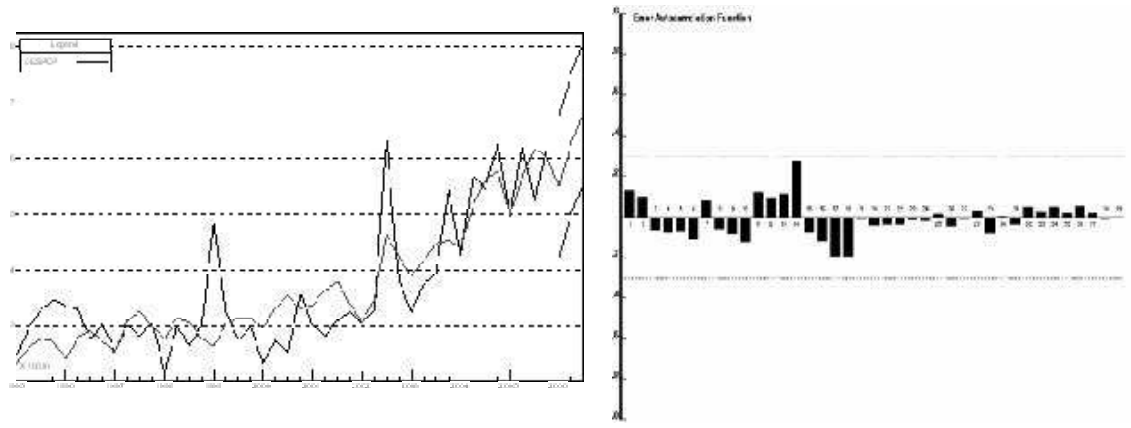

Fonte: Elaboração própria a partir do FPW

\section{Figura 8}

Ajustamento "Despesas Operacionais" (INDIVIDUAL) 


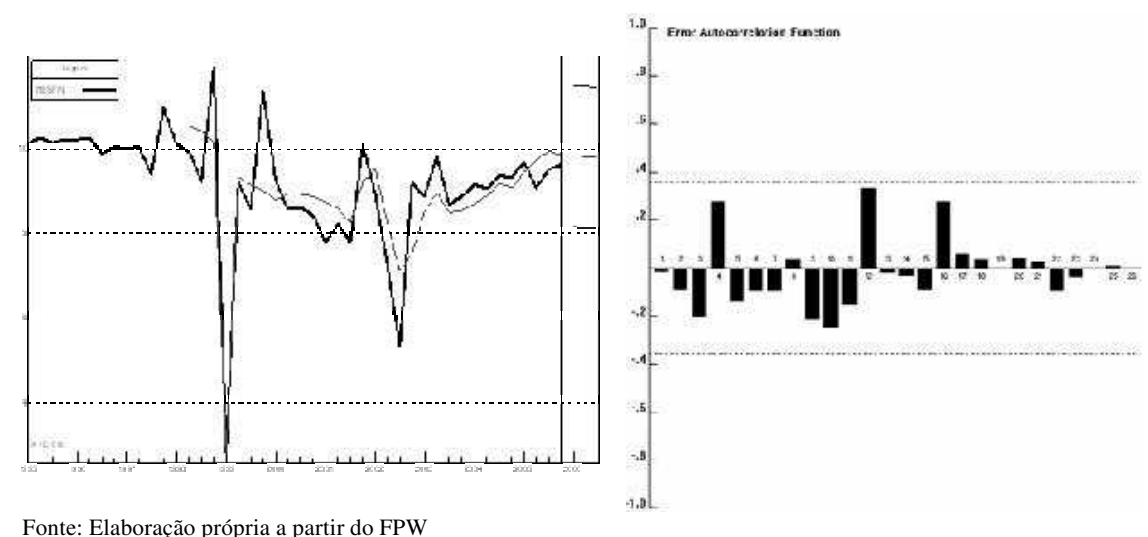

Figura 9

Ajustamento "Resultado Financeiro" (INDIVIDUAL)

\subsection{Estimação do comportamento médio esperado dos fatores de risco ma- croeconômicos}

Realizada a estimação em painel e em série de tempo e identificados os fatores de riscos relevantes entre os disponíveis, procedeu-se à estimação do comportamento futuro dos fatores de risco macroeconômicos. Conforme visto na estimação anterior, foram identificadas as seguintes variáveis explicativas (fatores de risco):
a) SELIC
b) PTAX
c) TNOTEAA
d) EXPAGREG
e) PIBCONSTCIVIL
f) SALARIONOM
g) HEDGECAMBIAL
h) DIVNAC
i) $\mathrm{TD} 2$
j) DUMMY1 (referente à quebra estrutural do regime de câmbio fixo para flu- tuante em 1999) 
Além das variáveis dependentes defasadas RECL_1, CMV_1, DESPOP_1 e RESFIN_1. As variáveis $g, h, i, j$ e as dependentes defasadas foram consideradas como "gerenciáveis", ou seja, passíveis de serem programadas/conhecidas a priori pela empresa. Portanto, os esforços nesta etapa concentraram-se nos valores esperados das variáveis SELIC, PTAX, TNOTEAA, EXPAGREG, PIBCONSTCIVIL e SALARIONOM. São apresentados a seguir os gráficos extraídos do software FPW com as previsões dos valores futuros desses fatores de riscos e seus respectivos correlogramas. ${ }^{5}$ Ressalta-se que as séries usadas nesta etapa da modelagem referem-se aos índices apurados a partir das variações trimestrais de cada série. Após a estimação dos índices futuros, esses foram novamente transformados em variações para integrar as previsões das contas componentes do fluxo de caixa.

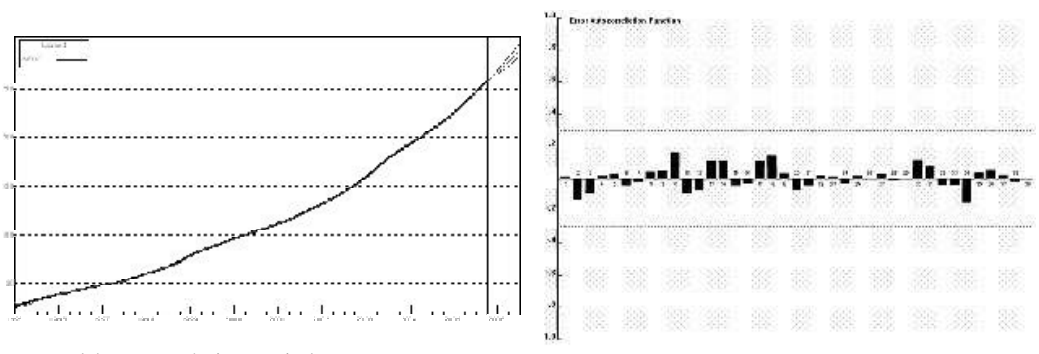

Fonte: Elaboração própria a partir do FPW

Figura 10

Previsão SELIC (Modelo: Holt exponential smoothing: Linear trend, No seasonality)

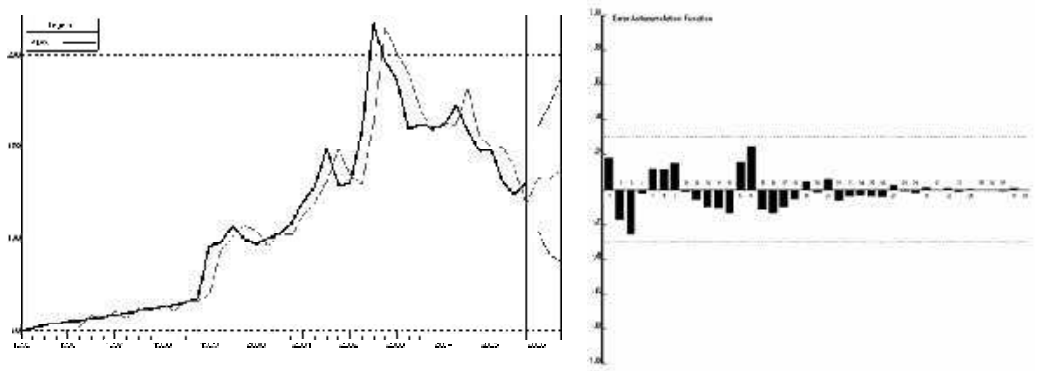

Fonte: Elaboração própria a partir do FPW

Previsão PTAX (Modelo: Regressão Dinâmica: 2 regressors, 1 lagged errors)

\footnotetext{
${ }^{5}$ Os outputs completos do FPW podem ser disponibilizados mediante solicitação.
} 
Perobelli, F., Januzzi, F., Berbert, L., Medeiros, D.

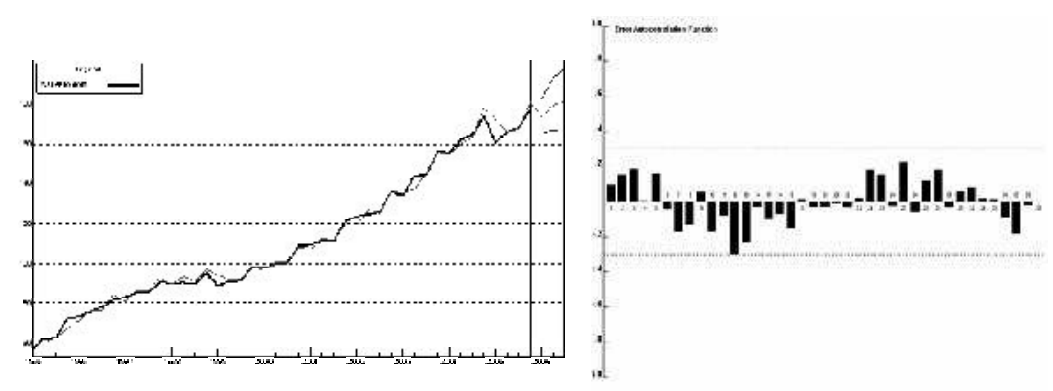

Fonte: Elaboração própria a partir do FPW

Figura 12

Previsão SALARIONOM (Modelo: ARIMA $(0,1,0) *(2,0,1))$

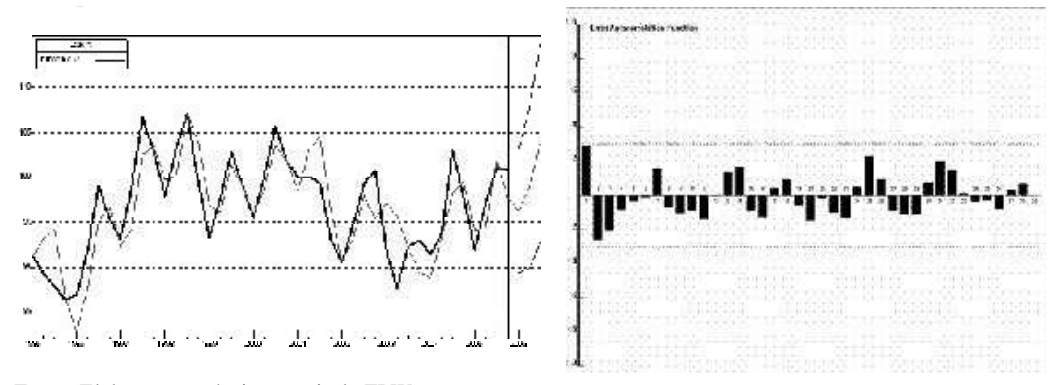

Fonte: Elaboração própria a partir do FPW

Figura 13

Previsão PIBCONSTCIVIL (Modelo: Exponential smoothing: No trend, Multiplicative seasonality)

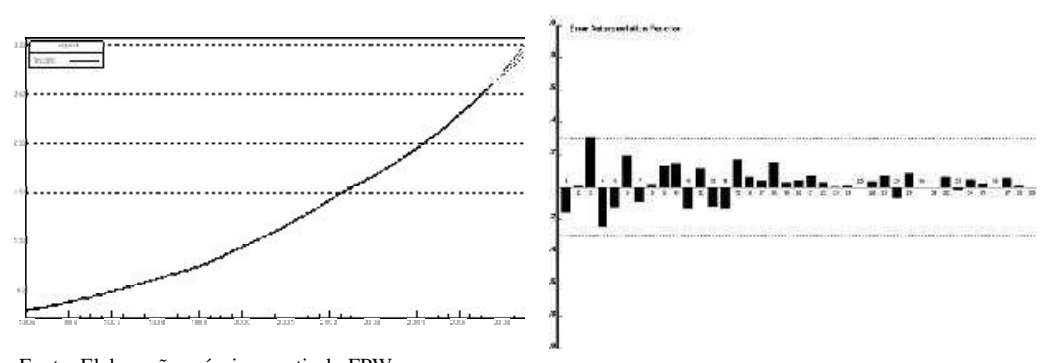

Fonte: Elaboração própria a partir do FPW

Figura 14

Previsão TNOTEAA (Modelo: ARIMA $(1,1,0) *(0,1,1))$

186

Revista Brasileira de Finanças 2007 Vol. 5, No. 2 


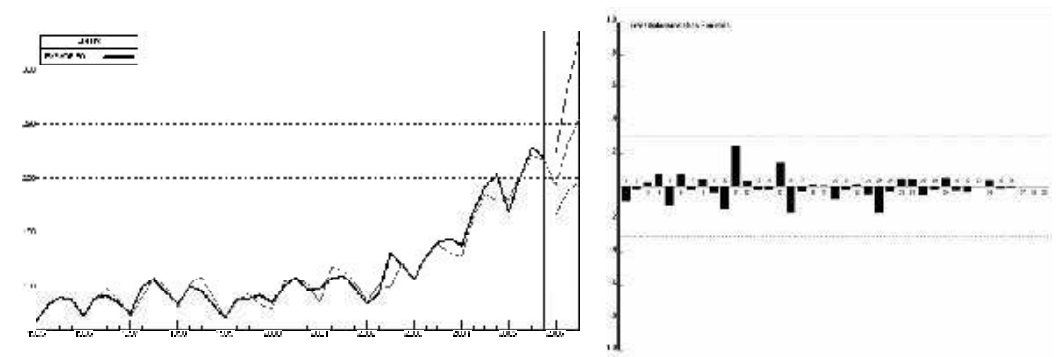

Fonte: Elaboração própria a partir do FPW

Figura 15

Previsão EXPAGREG (Modelo: Multiplicative Winters: Linear trend, Multiplicative seasonality)

\subsection{Simulações}

Conforme anteriormente descrito, após estimação das médias para os fatores de risco 3 passos à frente $(t=3)$, passou-se à simulação da distribuição futura de tais fatores, em cada um dos 3 trimestres. Para tanto, adotaram-se 2 procedimentos: simulação de 1000 choques aleatórios extraídos da distribuição escolhida pelo software Crystal Ball a partir da distribuição do próprio fator e simulação de 1000 choques aleatórios extraídos da distribuição dos erros do fator, a serem somados à previsão pontual do fator de risco. As distribuições escolhidas por fator, em nível e via erros, de acordo com o teste Qui-quadrado (ChiSquare), encontram-se dispostas na tabela abaixo. 
Tabela 1

Distribuições escolhidas para os fatores e para os erros de previsão dos fatores de risco (simulação em nível e no erro, em painel e individual) e para as variáveis dependentes (bootstrap)

\begin{tabular}{|c|c|c|c|}
\hline Séries & $\begin{array}{c}\text { Distribuição } \\
\text { de probabilidade }\end{array}$ & ChiSquare & Parâmetros \\
\hline Receita líquida & beta & 7,55 & Minimum=407.317,31; Maximum=2.059.153,81; Alpha $=0,3 ;$ Beta $=0,87227$ \\
\hline CMV & beta & 11,74 & Minimum $=282.928,31 ;$ Maximum $=1.061 .869,01 ;$ Alpha $=0,3 ;$ Beta $=0,73497$ \\
\hline Despesas Operacionais & gamma & 10 & Location $=21.480,10 ;$ Scale $=8.993,37 ;$ Shape $=1,68623$ \\
\hline Resultado Financeiro & logistic & 5,6 & Mean $=-58.624,48 ;$ Scale $=8.993,37 ;$ Shape $=1,68623$ \\
\hline Selic - Nível & Weibull & 3,05 & Location $=3,54 ;$ Scale $=2,04 ;$ Shape $=0,94973$ \\
\hline Selic - Erro & $t$ student & 6,43 & Midpoint $=0,12 ;$ Scale $=0,25 ;$ Deg. Freedom $=1$ \\
\hline PTAX - Nível & triangular & 14,5 & Minimum $=47,91 ;$ Likeliest $=49,78 ;$ Maximum $=241,91$ \\
\hline PTAX - Erro & Weibull & 22,93 & Location $=174,31 ;$ Scale $=180,66 ;$ Shape $=15$ \\
\hline Salarionom - Nível & gamma & 7,14 & Location $=46,73 ;$ Scale $=19,45 ;$ Shape $=3,35082$ \\
\hline Salarionom - Erro & $t$ student & 2,84 & Midpoint $=-0,18$; Scale $=1,62$; Deg. Freedom $=3,20208$ \\
\hline PIBConstCivil - Nível & gamma & 5,6 & Location $=65,06 ;$ Scale $=0,92 ;$ Shape $=34,43123$ \\
\hline $\begin{array}{l}\text { PIBConstCivil - Erro } \\
\text { PIBC }\end{array}$ & logística & 3,67 & Mean $=0,08 ;$ Scale $=2,29$ \\
\hline TNOTEAA - Nível & beta & 0,59 & Minimum $=31,32 ;$ Maximum $=266,90 ;$ Alpha $=0,64715 ;$ Beta $=1,13761$ \\
\hline TNOTEAA - Erro & max extreme & 3,87 & Likeliest $=-0,16$; Scale $=0,61$ \\
\hline Expagreg - Nível & max extreme & 11,23 & Likeliest $=96,98 ;$ Scale $=25,26$ \\
\hline Expagreg - Erro & logística & 2,42 & Mean $=-0,05 ;$ Scale $=6,30$ \\
\hline
\end{tabular}

Fonte: Elaboração própria a partir do software Crystal Ball 
Posteriormente, os valores estimados dos fatores de risco foram inseridos nas equações das variáveis RECL, CMV, DESPOP, RESFIN, dando origem às distribuições dessas contas. Da mesma forma, simulados os valores de todas contas, essas foram somadas (a cada simulação) para dar origem à variável FC. Algumas informações importantes a respeito do método de simulação a partir da distribuição do fator (simulação em nível):

a) os valores pontuais (médios) assumidos pelas variáveis macroeconômicas na simulação são os valores projetados pelos modelos de séries de tempo escolhidos para essas variáveis;

b) valores adicionais da distribuição para as variáveis macroeconômicas foram simulados a partir da melhor distribuição teórica encontrada pelo Crystal Ball, escolhida a partir da série histórica do fator em nível. As médias das variáveis independentes, bem como seus demais demais valores simulados, são iguais para todas as variáveis dependentes (a cada simulação, os valores simulados alimentam conjuntamente todas as equações de interesse: RECL, CMV, DESPOP, RESFIN e FC, se o fator de risco em questão constar de sua célula de previsão);

c) nas simulações dos fatores de risco, os valores simulados são correlacionados a partir da matriz de correlação das variáveis macroeconômicas em nível;

d) as variáveis dependentes defasadas não são correlacionadas e nem simuladas, sendo consideradas valores fixos. Cabe ressaltar que a previsão da variável dependente no trimestre anterior será multiplicada pelo coeficiente da variável dependente defasada e será um insumo para a projeção seguinte, mantendo ainda seu caráter fixo;

e) variáveis de controle da empresa foram consideradas fixas: dívida nacional, hedge cambial e dummy de trimestre;

f) em adição às variávies independentes, soma-se a cada equação de previsão de interesse (RECL, CMV, DESPOP e RESFIN) o valor do erro da variável dependente. Cabe ressaltar que o erro também é uma variável aleatória que segue uma distribuição determinada pela sua série histórica. Os valores pontuais do erro, utilizados como base na simulação, foram os valores médios dos erros históricos;

g) o erro da variável dependente só foi correlacionado com as variáveis macroeconômicas em nível quando o valor da correlação entre eles foi superior a 0,30. Abaixo esses valores para a empresa USIMINAS (painel e série de tempo): 


\begin{tabular}{lccc} 
Painel: & & & \\
\hline & PTAX & SELIC & SALARIONOM \\
\hline Erro RECL & $-0,12096$ & $-0,12277$ & 0,12579 \\
Erro CMV & & $-0,1424$ & 0,19073 \\
Erro DESPOP & 0,24396 & & 0,36264 \\
Erro RESFIN & & 0,33629 & \\
\hline
\end{tabular}

Série de Tempo:

\begin{tabular}{lccccc}
\hline & PTAX & TNOTEAA & SALARIONOM & EXPAGREG & PIBCONSTCIVIL \\
\hline Erro RECL & & $-0,0373$ & $-0,00121$ & & \\
Erro CMV & & & $-0,11311$ & & \\
Erro DESPOP & $-0,22819$ & & & $-0,22311$ & $-0,42213$ \\
Erro RESFIN & 0,16734 & & & & \\
\hline
\end{tabular}

Algumas informações importantes a respeito do método de simulação a partir da distribuição do erro do fator (simulação do erro):

a) as variáveis macroeconômicas são as projeções dessas variáveis (médias estimadas pelos modelos autoprojetivos) acrescidas de seus erros, que são simulados conforme distribuição da série do próprio erro do modelo para o fator;

b) todos os erros das variáveis macroeconômicas foram correlacionados entre si, conforme correlação histórica observada entre eles;

c) na simulação, os valores pontuais dos erros foram estimados por meio da média histórica desses erros;

d) novamente as variáveis dependentes defasadas não são correlacionadas e nem simuladas, sendo consideradas valores fixos. A previsão da variável dependente no trimestre anterior será multiplicada pelo coeficiente da variável dependente defasada e será o insumo para a projeção seguinte, mantendo ainda seu caráter fixo;

e) novamente variáveis de controle da empresa foram consideradas fixas: dívida nacional, hedge cambial e dummy de trimestre;

f) novamente, em adição às variávies independentes, soma-se a cada equação de previsão de interesse (RECL, CMV, DESPOP e RESFIN) o valor do erro da variável dependente. Cabe ressaltar que o erro também é uma variável aleatória que segue uma distribuição determinada pela sua série histórica. Os valores pontuais do erro, utilizados como base na simulação, foram os valores médios dos erros históricos;

g) novamente o erro da variável dependente só foi correlacionado com o erro da variável macroeconômica quando o valor da correlação foi superior a 0,30. Abaixo, esses valores para USIMINAS (painel e série de tempo): 


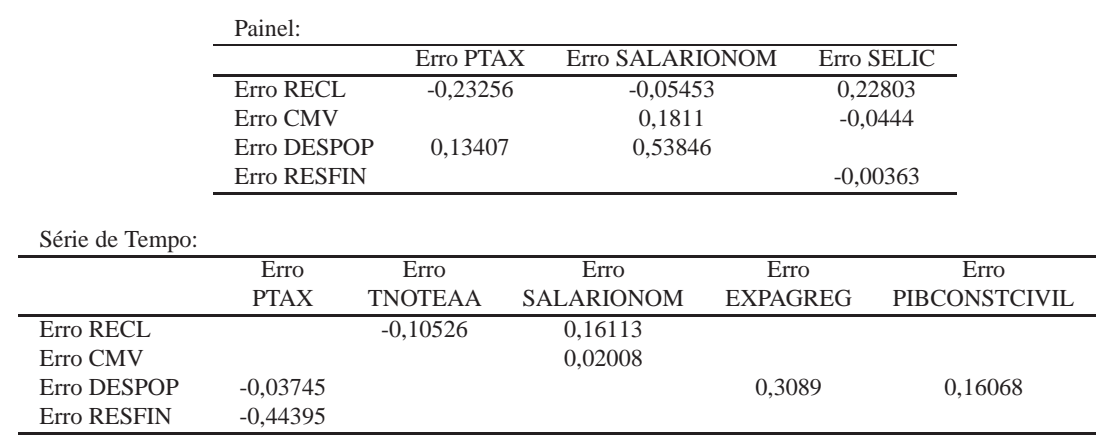

Além das simulações realizadas a partir de modelos, empregou-se também a simulação do tipo bootstrap, em que os quatro componentes do FC (RECL, CMV, DESPOP e RESFIN) foram simulados a partir de suas distribuições históricas apenas (sem determinação de seus valores futuros a partir de modelos). A matriz de correlação histórica entre as quatro contas foi usada como filtro nessa simulação. As equações de previsão, tal como foram usadas na simulação, estão sumarizadas abaixo:

$$
\begin{aligned}
& \text { Painel - Nível } \\
& R E C L_{\text {PainelNível }, t}=5861,23 \text { SALARIONOM } M_{t}-2118,93 \text { PTAX }_{t} \\
& +\quad \text { 0,99RECL } L_{\text {PainelNível, } t-1}-9835,63 S E L I C_{t} \\
& +\quad 32598,07 T D 2+48734,63+\epsilon_{t} \\
& C M V_{\text {PainelNível }, t}=2937,53 \text { SALARIONOM } \\
& +\quad 0,98 C M V_{\text {PainelNível }, t-1} \\
& \text { - 4152,26SELIC }+28543,94 T D 2+24888,9 \\
& +\epsilon_{t} \\
& \text { DESPOP } \text { PainelNível }, t=853,2125 \mathrm{SALARIONOM}_{t} \\
& +\quad \text { 0,94 DESPOP PainelNível, } t-1+255,577 \mathrm{PTAX}_{t} \\
& + \text { 3251,66 HEDGECAMBIAL } L_{t}+\epsilon_{t} \\
& R E S F I N_{\text {PainelNível }, t}=0,08 R E S F I N_{\text {PainelNível }, t-1} \\
& \text { - 0,03 DIVNAC } 4 \text { T2006 - 8037,59 SELIC } C_{t}+\epsilon_{t}
\end{aligned}
$$


Painel - Erro

$$
\begin{aligned}
& R E C L_{\text {PainelErro, } t}=5861,23\left(\hat{S} A L A R I O N O M_{t}+\epsilon_{\text {Salarionom }}\right) \\
& \text { - 2118,93( } \left.\hat{P} T A X_{t}+\epsilon_{P t a x}\right) \\
& +\quad 0,99 \hat{R} E C L_{\text {PainelErro, } t-1} \\
& \text { - } 9835,63\left(\hat{S} E L I C_{t}+\epsilon_{\text {Selic }}\right) \\
& +\quad 32598,07 T D 2+48734,63+\epsilon_{t} \\
& C M V_{\text {PainelErro, } t}=2937,53\left(\hat{S} A L A R I O N O M_{t}+\epsilon_{\text {Salarionom }}\right) \\
& +\quad 0,98 \hat{C} M V_{\text {PainelErro }, t-1} \\
& \text { - } 4152,26\left(\hat{S} E L I C_{t}+\epsilon_{\text {Selic }}\right) \\
& +\quad 28543,94 T D 2+24888,9+\epsilon_{t} \\
& D_{\text {ESPOP PainelErro }, t}=853,2125\left(\hat{S} A L A R I O N O M_{t}+\epsilon_{\text {Salarionom }}\right) \\
& +\quad 0,94 \hat{D} E S P O P_{\text {PainelErro, } t-1} \\
& +255,577\left(\hat{P} T A X_{t}+\epsilon_{P t a x}\right) \\
& +\quad 3251,66 \text { HEDGECAMBIAL } L_{t}+\epsilon_{t} \\
& \text { RESFIN } N_{\text {PainelErro, } t}=0,08 \hat{R} E S F I N_{\text {PainelErro }, t-1} \\
& \text { - 0,03DIVNAC } 4 \text { T2006 } \\
& \text { - } 8037,59\left(\hat{S} E L I C_{t}+\epsilon_{\text {Selic }}\right)+\epsilon_{t}
\end{aligned}
$$

Individual - Nível

$$
\begin{aligned}
& R E C L_{\text {IndividualNível }, t}=11155,03 \mathrm{SALARIONOM}_{t} \\
& \text { - 3591,77 TNOTEAAt } \\
& +\quad 0,75 R E C L_{\text {IndividualNível, } t-1}-601057,26+\epsilon_{t}
\end{aligned}
$$




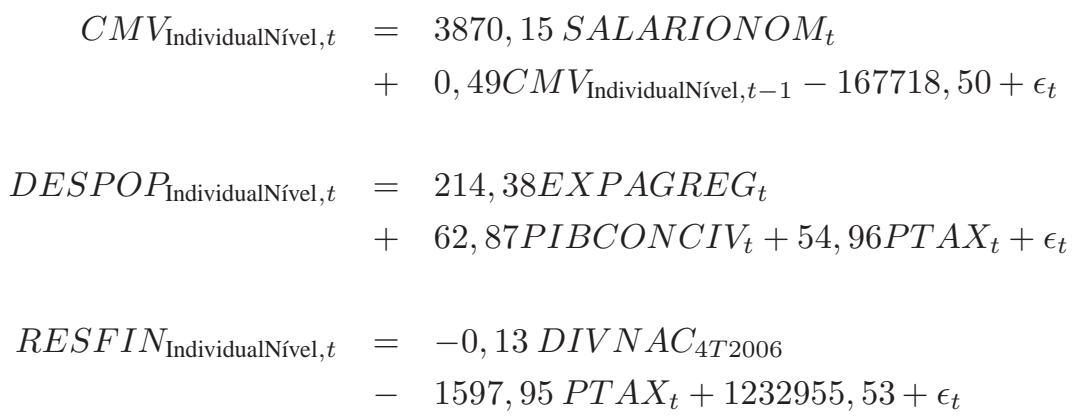

Individual - Erro

$$
\begin{aligned}
R E C L_{\text {IndividualErro }, t} & =11155,03\left(\hat{S} A L A R I O N O M_{t}+\epsilon_{\text {Salarionom }}\right) \\
& -3591,77\left(\hat{T} N O T E A A_{t}+\epsilon_{\text {Tnoteaa }}\right) \\
& +0,75 \hat{R} E C L_{\text {IndividualErro }, t-1}-601057+\epsilon_{t} \\
& =3870,15\left(\hat{S} A L A R I O N O M_{t}+\epsilon_{\text {Salarionom }}\right) \\
& +0,49 \hat{C} M V_{\text {IndividualErro }, t-1}-167718,50+\epsilon_{t} \\
& =214,38\left(\hat{E} X P A G R E G_{t}+\epsilon_{\text {Expagreg }}\right) \\
\left.D E S P O P_{\text {IndividualErro }, t}\right) & 62,87\left(\hat{P} I B C O N C I V_{t}+\epsilon_{P I B c o n c i v}\right) \\
& +54,96\left(\hat{P} T A X_{t}+\epsilon_{P t a x}\right)+\epsilon_{t} \\
R E S F I N_{\text {IndividualErro, } t} & =-0,13 D I V N A C_{4 T 2006} \\
& -1597,95\left(\hat{P} T A X_{t}+\epsilon_{P t a x}\right) \\
& +1232955,53+\epsilon_{t}
\end{aligned}
$$

$F C_{t}=R E C L_{t}-C M V_{t}-D E S P O P_{t}+R E S F I N_{t}$

Fonte: Elaboração própria a partir de outputs do STATA 8.0 e FPW 


\section{Resultados}

A seguir, serão apresentados os resultados gráficos das simulações para o fluxo de caixa em cada um dos trimestres utilizados para backtesting (1T06, 2T06 e 3T06), segundo os cinco (05) procedimentos testados:

a) Estimação dos Fatores de Risco usando Painel - Simulação em Nível

b) Estimação dos Fatores de Risco usando Painel - Simulação em Erro

c) Estimação dos Fatores de Risco usando Modelos Individuais - Simulação em Nível

d) Estimação dos Fatores de Risco usando Modelos Individuais - Simulação em Erro

e) Simulação via Bootstrap

Ressalta-se que a legenda apresentada nas figuras refere-se a:

a) Base Case: estimação pontual obtida via Estimação em Painel ou Modelo Individual;

b) Mean: valor médio da distribuição empírica de cada conta;

c) Valor real: valor da conta no trimestre. 

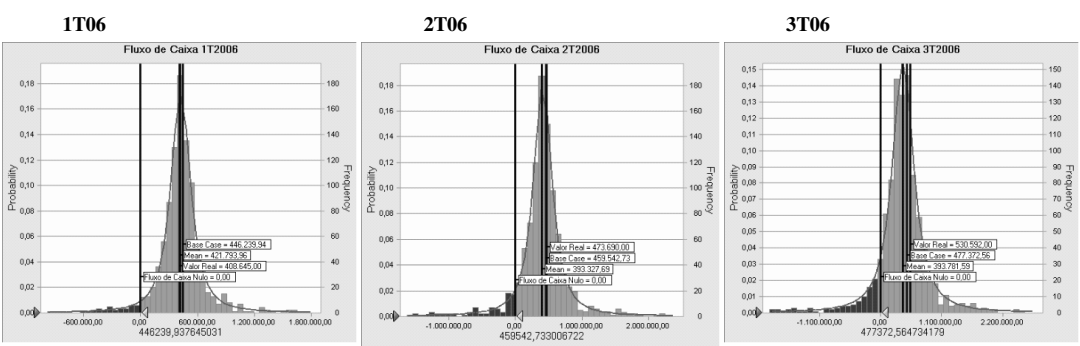

Fonte: Elaboração própria a partir do Crystal Ball

Figura 16

a) Estimação dos fatores de risco usando painel - simulação em nível
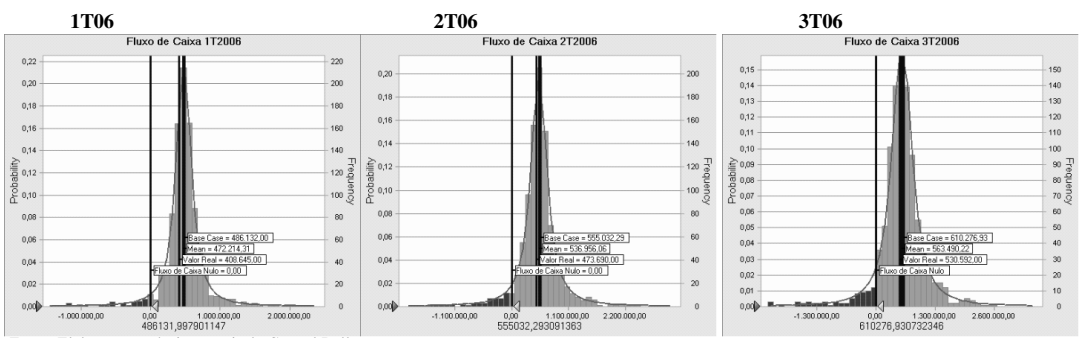

Figura 17

b) Estimação dos fatores de risco usando painel - simulação em erro
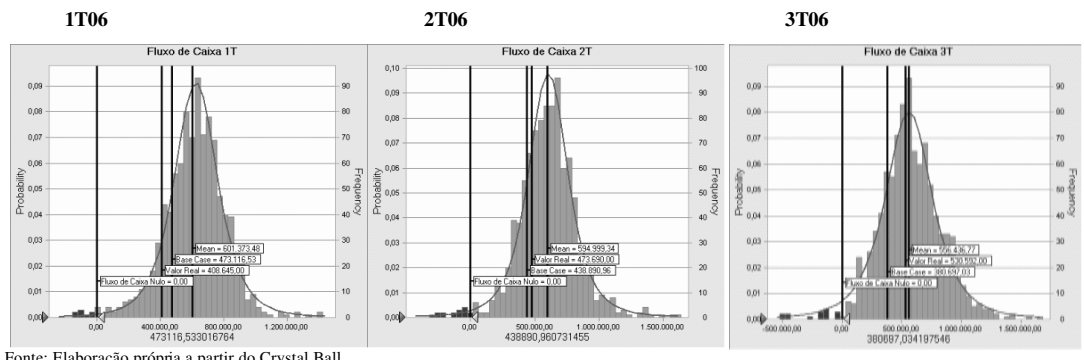

Figura 18

c) Estimação dos fatores de risco usando modelos individuais - simulação em nível 

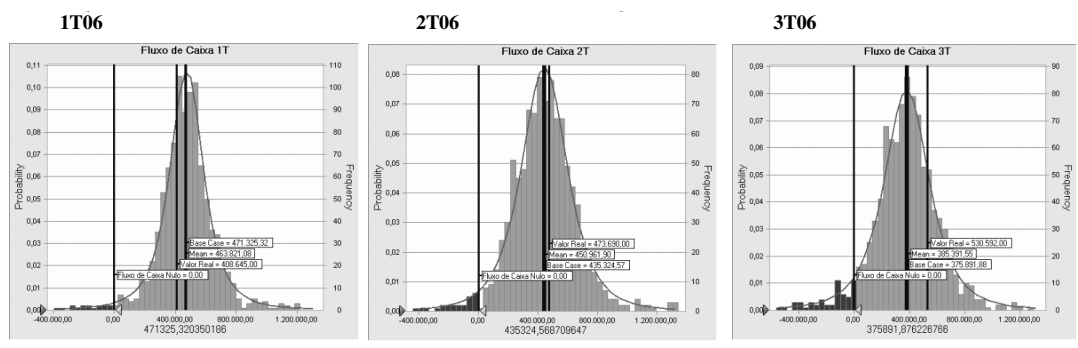

Fonte: Elaboração própria a partir do Crystal Ball

Figura 19

d) Estimação dos fatores de risco usando modelos individuais - simulação em erro
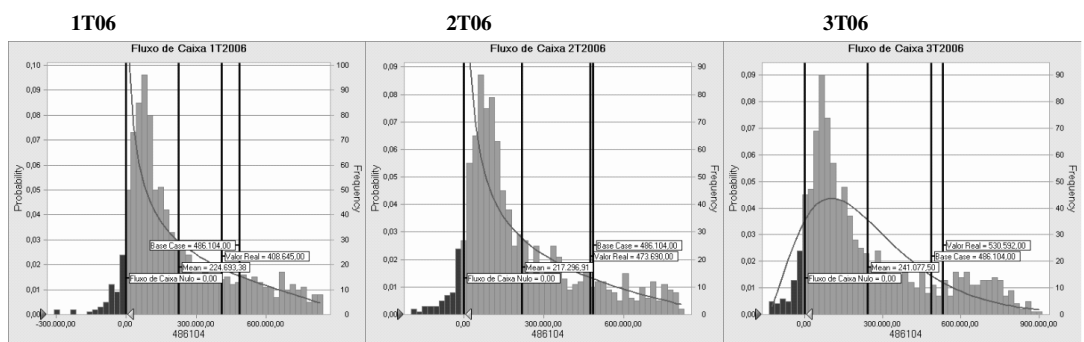

Fonte: Elaboração própria a partir do Crystal Bal

Figura 20

e) Simulação via bootstrap 


\begin{tabular}{|c|c|c|c|c|c|c|}
\hline Conta/Método & & & & & e Erro & \\
\hline & $1 \mathrm{~T}$ & $2 \mathrm{~T}$ & $3 \mathrm{~T}$ & 1T & $2 \mathrm{~T}$ & $3 \mathrm{~T}$ \\
\hline RECL (Base Case) & & & & & & \\
\hline $\begin{array}{l}\text { Painel Nivel } \\
\text { Painel Erro }\end{array}$ & $\begin{array}{l}1.569 .262 \\
1.609 .439\end{array}$ & $\begin{array}{l}1.621 .1470 \\
1.715860\end{array}$ & $\begin{array}{l}1.638 .911 \\
1.769 .228\end{array} \mid$ & $\begin{array}{r}-2,4 \% \\
0.1 \%\end{array}$ & $\begin{array}{l}-3,3 \% \\
2,3 \%\end{array}$ & $-4,2 \%$ \\
\hline $\begin{array}{l}\text { Painel Erro } \\
\text { Individual Nivel }\end{array}$ & 1.537 .709 & 1.532 .568 & 1.505 .443 & $-4,4 \%$ & $-8.6 \%$ & \\
\hline \begin{tabular}{|l} 
Individual Erro \\
Indival
\end{tabular} & 1.535 .182 & 1.528 .156 & 1.499 .626 & $-4,5 \%$ & $-8,9 \%$ & $\begin{array}{l}-12,0 \% \% \\
-124 \%\end{array}$ \\
\hline RECL (Mean) & & & & & & \\
\hline Painel Nivel & 1.563 .716 & 1.565 .751 & 1.564 .479 & $-2,7 \%$ & $-6,6 \%$ & $-8,6 \%$ \\
\hline Painel Erro & 1.615 .506 & 1.719 .669 & 1.753.148 & $0,5 \%$ & $2,6 \%$ & $2,5 \%$ \\
\hline Individual Nível & 1.403 .489 & 1.278 .435 & 1.182 .504 & $-12,7 \%$ & $-23,7 \%$ & $-30,9 \%$ \\
\hline Individual Erro & 1.533 .742 & 1.525 .542 & 1.497 .322 & $-4,6 \%$ & $-9,0 \%$ & $-12,5 \%$ \\
\hline RECL (Real) & 1.607 .694 & 1.676 .619 & 1.710 .994 & $0.0 \%$ & $0.0 \%$ & $0.0 \%$ \\
\hline CMV (Base Case) & & & & & & \\
\hline Painel Nivel & $\begin{array}{l}984.423 \\
982.969 \\
\mathrm{~S}\end{array}$ & $\begin{array}{l}1.020 .929 \\
1.018 .047\end{array}$ & $\begin{array}{l}1.022 .138 \\
1.077 .852\end{array}$ & $\begin{array}{l}-8,1 \% \% \\
-8,2 \%\end{array}$ & $\begin{array}{l}-7,7 \% \\
-7.9 \%\end{array}$ & $\begin{array}{l}-7,4 \% \\
-7,8 \%\end{array}$ \\
\hline \begin{tabular}{|l} 
Painel Erro \\
Individual Nivel
\end{tabular} & $\begin{array}{l}98.2969 \\
992.757\end{array}$ & $\begin{array}{l}1.018 .047 \\
1.015 .089\end{array}$ & $\begin{array}{l}1.017 .852 \\
1.031 .745\end{array}$ & $\begin{array}{l}-8,2 \% \\
-7,3 \%\end{array}$ & $\begin{array}{l}-7,9 \% \\
-8.2 \%\end{array}$ & $\begin{array}{l}-7.8 .8 \% \\
-6.5 \%\end{array}$ \\
\hline $\begin{array}{l}\text { Individual Erro } \\
\text { Int }\end{array}$ & $\begin{array}{l}992.067 \\
99.137\end{array}$ & $\begin{array}{l}1.014 .060 \\
1.060\end{array}$ & $\begin{array}{l}1.030 .550 \\
1.030\end{array}$ & $-7,4 \%$ & $\begin{array}{l}-0,210 \\
-8,3 \%\end{array}$ & $\begin{array}{l}-0,0,0 \% \\
-6,6 \%\end{array}$ \\
\hline CMV (Mean) & & & & & & \\
\hline Painel Nível & 984.715 & 1.009 .025 & 1.002 .501 & $-8,1 \%$ & $-8,7 \%$ & $-9,2 \%$ \\
\hline Painel Erro & 983.374 & 1.017 .862 & 1.019 .172 & $-8,2 \%$ & $-7,9 \%$ & $-7,6 \%$ \\
\hline Individual Nível & 742.395 & 627.048 & 556.641 & $-30,7 \%$ & $-43,3 \%$ & $-49,6 \%$ \\
\hline Individual Erro & 986.085 & 997.271 & 1.024 .688 & $-8,0 \%$ & $-9,8 \%$ & $-7,1 \%$ \\
\hline CMV (Real) & 1.071 .346 & 1.105 .649 & 1.103 .592 & $0.0 \%$ & $0,0 \%$ & $0.0 \%$ \\
\hline DESPOP (Base Case) & & & & & & \\
\hline Painel Nivel & 58.556 & 58.733 & 58.195 & $-15,6 \%$ & $-19,5 \%$ & $-9,8 \%$ \\
\hline Painel Erro & 58.446 & 58.521 & 57.887 & $-15,7 \%$ & $-19,7 \%$ & $-10,2 \%$ \\
\hline Individual Nível & 54.866 & 62.993 & 68.457 & $-20,9 \%$ & $-13,6 \%$ & $6,1 \%$ \\
\hline $\begin{array}{l}\text { Individual Erro } \\
\text { DEPPOP(Mean) }\end{array}$ & 54.820 & 62.947 & 68.411 & $-21,0 \%$ & $-13,7 \%$ & $6,1 \%$ \\
\hline Painel Nivel & 61.244 & 61.017 & 60.418 & $-11,7 \%$ & $-16,3 \%$ & $-6,3 \%$ \\
\hline Painel Erro & 58.857 & 59.874 & 59.155 & $-15,1 \%$ & $-17,9 \%$ & $-8,3 \%$ \\
\hline Individual Nivel & 36.028 & 36.613 & 36.687 & $-48,0 \%$ & $-49.8 \%$ & $-43,1 \%$ \\
\hline Individual Erro & 55.066 & 62.683 & 68.679 & $-20.6 \%$ & $-14.0 \%$ & $6.5 \%$ \\
\hline DESPOP (Real) & 69.349 & 72919 & 64,492 & $0.0 \%$ & $0.0 \%$ & $0.0 \%$ \\
\hline $\begin{array}{l}\text { RESFIN (Base Case) } \\
\end{array}$ & & & & & & \\
\hline Painel Nivel & -80.042 & -82.264 & -81.205 & $37,2 \%$ & $237,7 \%$ & $559,2 \%$ \\
\hline Painel Erro & -81.891 & -84.258 & $-83.211 \mid$ & $40,3 \%$ & $245,9 \%$ & $575,5 \%$ \\
\hline Individual Nivel & -16.969 & -15.594 & -24.543 & $-70,9 \%$ & $-36,0 \%$ & $99,2 \%$ \\
\hline Individual Erro & -16.969 & -15.824 & -24.773 & $-70,9 \%$ & $-35,0 \%$ & $101,1 \%$ \\
\hline $\mid \begin{array}{l}\text { RESFIN (Mean) } \\
\text { Painel Nivel }\end{array}$ & -86.360 & -88.466 & -92.382 & $48.0 \%$ & $263.1 \%$ & $650.0 \%$ \\
\hline Painel Erro & -78.072 & -72.374 & -75.256 & $33,8 \%$ & $197,1 \%$ & $510.9 \%$ \\
\hline Individual Nível & 1.260 & -5.896 & 2.483 & $-102,2 \%$ & $-75,8 \%$ & $-120,2 \%$ \\
\hline Individual Erro & -24.826 & -27.398 & -29.694 & $-57.5 \%$ & $12.5 \%$ & $141.1 \%$ \\
\hline RESFIN (Real) & -58.354 & -24.361 & -12.318 & $0.0 \%$ & $0.0 \%$ & $0.0 \%$ \\
\hline FCF (Base Case) & & & & & & \\
\hline Painel Nivel & 446.239 & 459.542 & 477.372 & $9,2 \%$ & $-3,0 \%$ & $-10,0 \%$ \\
\hline Painel Erro & 486.132 & 555.032 & 610.276 & $19,0 \%$ & $17.2 \%$ & $15,0 \%$ \\
\hline Individual Nível & 473.116 & 438.890 & $380.697 \mid$ & $15.8 \%$ & $-7.3 \%$ & $-28,3 \%$ \\
\hline Individual Erro & 471.325 & 435.324 & 375.891 & $15,3 \%$ & $-8,1 \%$ & $-29,2 \%$ \\
\hline FCF (Mean) & & & & & & \\
\hline Painel Nivel & 421.794 & 393.328 & 393.782 & $3,2 \%$ & $-17,0 \%$ & $-25,8 \%$ \\
\hline Painel Erro & 472.214 & 536.956 & 563.490| & $15,6 \%$ & $13,4 \%$ & $6,2 \%$ \\
\hline Individual Nível & 601.373 & 594.999 & 556.437 & $47,2 \%$ & $25,6 \%$ & $4,9 \%$ \\
\hline Individual Erro & 463.821 & 450.962 & 385.392 & $13,5 \%$ & $-4,8 \%$ & $-27,4 \%$ \\
\hline FCF (Mean Bootstrap) & 224.693 & 217.297 & $241.077 \mid$ & $-45,0 \%$ & $-54,1 \%$ & $-54,6 \%$ \\
\hline FCF (Real) & 408.645 & 473.690 & 530.592 & $0,0 \%$ & $0,0 \%$ & $0,0 \%$ \\
\hline
\end{tabular}

Figura 21

Comparativo dos modelos

Tomando-se por base a Figura 21, algumas observações podem ser feitas a respeitos dos métodos de estimação do fluxo de caixa em risco:

a) apesar das discrepâncias entre os valores estimados, tanto na previsão (base case), quanto na média da distribuição simulada (mean), o fluxo de caixa em risco nos três trimestres, segundo todos os métodos (exceto para o 3T, "Fatores de Risco usando Painel - Simulação em Nível", que chegou a menos de 15\%), para Usiminas foi inferior a 10\% (menos de 10\% de chance de observar um fluxo de caixa inferior a zero no trimestre), conforme Quadro 4 abaixo;

b) as distribuições simuladas mais problemáticas, segundo critério "diferença entre a média da distribuição (mean) e o valor real" foram as geradas pelo 
método "Fatores de Risco usando Modelos Individuais - Simulação em Nível";

c) as distribuições simuladas mencionadas no item b só demonstraram melhor performance que as simuladas segundo bootstrap;

d) os melhores resultados de projeção e de simulação encontrados foram os relacionados à conta "Receita Líquida (RECL)". Para essa conta, a melhor performance foi a do método "Fatores de Risco usando Painel - Simulação Erro";

e) os piores resultados de projeção e de simulação encontrados foram os relacionados à conta "Resultado Financeiro (RESFIN)". Isso vem confirmar um resultado já esperado: como as decisões financeiras da empresa costumam oscilar segundo oportunidades de mercado, o comportamento dessa conta é bastante imprevisível para o pesquisador externo à empresa;

f) os resultados encontradas para as contas "Custo das Mercadorias Vendidas (CMV)" e "Despesas Operacionais (DESPOP)" apresentaram um movimento de reversão, com os resultados do terceiro trimestre de projeção melhores que os do primeiro, segundo todos os métodos;

g) para a empresa apresentada, à exceção do método bootstrap, que obteve a pior performance, e do método "Fatores de Risco usando Modelos Individuais - Simulação em Nível”, que gerou distribuições com médias bastante díspares dos valores reais, os demais foram satisfatórios na tarefa de gerar uma distribuição ao redor das previsões pontuais e dos respectivos valores reais observados no backtesting, principalmente considerando-se as restrições de acesso a informações gerencias e a séries relevantes enfrentadas pelo pesquisador externo à empresa.

\begin{tabular}{lccc}
\multicolumn{4}{c}{ Probabilidades de $\mathrm{FC}<0$ em cada método } \\
\hline \multicolumn{1}{c}{ Métodos } & $3 \mathrm{~T}$ & $2 \mathrm{~T}$ & $1 \mathrm{~T}$ \\
\hline Painel nível & 12,28 & 9,01 & 4,82 \\
Painel erro & 8,85 & 7,49 & 5,67 \\
Individual nível & 3,15 & 2,88 & 2,01 \\
Individual erro & 5,92 & 3,65 & 3,06 \\
Bootstrap & 7,95 & 6,08 & 6,37 \\
\hline
\end{tabular}

\section{Observações Finais}

Froot et alii (1994) enfatizam que um programa de gerenciamento de riscos de mercado deve ter como único objetivo assegurar um planejamento acurado dos recursos necessários para os investimentos da empresa e a manutenção de sua atividade produtiva. Como subproduto relevante desse gerenciamento, os autores 
também destacam a capacidade que as empresas adquirem de avaliar quais riscos devem ser evitados, hedgeados ou simplesmente enfrentados por serem parte integrante de seu negócio.

Indo um pouco mais adiante, o guia para gerenciamento de riscos do JP Morgan \& Co.; Arthur Andersen LLP Financial Engineering Ltd (1997) enfatiza que, uma vez que as exposições a risco da empresa estejam identificadas e quantificadas, o próximo passo é trabalhar o perfil de risco da empresa. Essa remodelação passa, por exemplo, por alterações no perfil da dívida, compatibilização dos prazos e dos termos de pagamento e de recebimento, e adequação do cronograma de investimentos aos recursos disponíveis. Visando servir de ferramenta a tal gerenciamento, os métodos de determinação dos fluxos de caixa em risco aqui propostos, a despeito de terem sido empiricamente construídos de fora da empresa e de prescindirem de informações gerenciais preciosas - especialmente em relação aos valores futuros dos fatores de risco próprios - demonstram ser úteis aos gestores para avaliar o comportamento futuro de seus fatores de risco macroeconômicos e, principalmente, o reflexo de tal comportamento sobre os fluxos de caixa projetados. Munidos de tal metodologia, o budget plan elaborado pelos gestores é capaz de evoluir de um cenário único para uma distribuição de fluxos futuros, obtida pela consideração de movimentos diversos nas premissas do orçamento elaborado. Com isso, ganha-se um instrumento mais sofisticado de análise de sensibilidade. A sofisticação advém da consistência da previsão da média condicional dos fatores de risco macroeconômicos e dos choques simulados, ao contrário da análise de sensibilidade convencional, que insere choques não correlacionados em diversas variáveis relevantes - quando, na realidade, tais choques são totalmente correlacionados. Por meio do modelo geral aqui proposto é possível inserir no budget plan elaborado choques que mantenham a estrutura de correlação histórica entre as variáveis de interesse.

Como limitações inerentes à metodologia empregada nesse trabalho, destacam-se tanto a escolha a priori do escopo de candidatas a variáveis independentes como a parcimônia necessária na decisão de quais fatores de risco macroeconômico considerar na modelagem econométrica. Adicionalmente, não há garantias de que será sempre possível estimar o comportamento futuro dos fatores de risco. Especialmente quando o horizonte de previsão for de prazo mais longo, há restrições à eficácia de tais modelos.

Ainda no que se refere à eficácia dos modelos de séries de tempo e em painel, deve-se mencionar que tais modelos são fortemente baseados em informações passadas, sendo incapazes de prever choques inéditos. Os métodos aqui propostos, contudo, não excluem a possibilidade de que cenários de estresse sejam inseridos pelos gestores em seu budget plan, numa abordagem semelhante ao stress test empreendido pelas instituições financeiras em adição ao cálculo do VaR. 


\section{Referências}

Bauman, J., Saratore, S., \& Liddle, W. (1999). A practical framework for corporate exposure management. In Brown, G. \& Chew, D., editors, Corporate Risk: Strategies and Management. Risk Publications, London.

Blundell, R. \& Bond, S. (1998). Initial conditions and moment restrictions in dynamic panel data models. Journal of Econometrics, 87(1):115-43.

Castro, A. (2002). Gerenciamento do risco de mercado para produtores de commodities no Brasil. Dissertação (Mestrado profissional em Administração) FGV-EAESP, São Paulo.

Enders, W. (1995). Applied Econometric Time Series. John Wiley \& Sons, Hoboken, NJ.

Froot, K., Scharfstein, D., \& Stein, J. (1994). A framework for risk management. Harvard Business Review, 72(6):91-102.

Hamilton, J. (1994). Time Series Analysis. Princeton University Press, New Jersey.

Hayt, G. \& Songs, S. (1995). Handle with sensitivity. Risk Magazine, 8(9):94-99.

JP Morgan \& Co.; Arthur Andersen LLP Financial Engineering Ltd (1997). The JP Morgan/Arthur Andersen Guide to Corporate Risk Management. Risk Publications, London.

La Roque, E., Lowenkron, A., Amadeo, E., \& Jensen, J. (2003). Cenários probabilísticos: Conjugando análise de riscos e projeções macroeconômicas. Documento técnico. Lista de riscos disponível em ¡http://www.listaderiscos.com.bri

Linsmeier, T. \& Pearson, N. (1997). Risk management disclosure. In Jameson, R., editor, Financial Risk and the Corporate Treasury - New Developments in Strategy and Control. Risk Publications, London.

Perobelli, F. \& Securato, J. (2005). Um modelo para gerenciamento de riscos em empresas não-financeiras. Revista de Administração de Empresas, 4:1-30.

Riskmetric Group (1999). LongRun technical document. www.riskmetrics.com.

Riskmetrics Group (1999). CorporateMetrics technical document. Disponível em http://www.riskmetrics.com.

Shapiro, A. \& Titman, S. (1999). An integrated approach to corporate risk management. In Brown, G. \& Chew, D., editors, Corporate Risk: Strategies and Management. Risk Publications, London.

Sims, C. (1980). Macroeconomics and reality. Econometrica, 48:1-49. 
Stein, J., Usher, S., Lagattuta, D., \& Youngen, J. (2001). A comparables approach to measuring cash-flow-at-risk for non-financial firms. Journal of Applied Corporate Finance, 13(4):8-17.

Stulz, R. \& Williamson, R. (1997). Identifying and quantifying exposures. In Jameson, R., editor, Financial Risk and the Corporate Treasury - New Developments in Strategy and Control. Risk Publications, London.

Varanda Neto, J. (2004). Determinação do valor em risco em empresas nãofinanceiras - estudo de caso de empresa geradora de energia. Anais do VIII SEMEAD, São Paulo.

Vermeulen, E. (1994). Corporate Risk Management: A Multi-Factor Approach. Thesis Publishers, Amsterdam. 


\section{Apêndice A}

\section{Detalhamento da Simulação}

Detalhadamente, tem-se que, conhecendo as realizações passadas dos fatores de risco constantes no vetor $\left(X_{j, t}\right)$ de fatores de risco, é possível acessar a distribuição futura desses fatores sorteando-se $n$ vetores $u$ de choques aleatórios independentes, cada um deles de tamanho $(j t \times 1)$, a partir da distribuição empírica de cada fator. Após cada sorteio, o vetor $u$ é "filtrado" pela matriz de covariância dos fatores em nível ou de seus erros $(\Sigma X)$, a partir da decomposição desta matriz, e somado à matriz de previsões dos fatores de risco $\left(\hat{X}_{j, t}\right)$.

De acordo com Hamilton (1994), toda matriz real positiva definida $(\Sigma X)$ pode ser decomposta em (1) uma matriz triangular inferior A com 1's na diagonal principal e (2) uma matriz diagonal $D$ com números positivos na diagonal principal de tal forma que:

$$
\Sigma_{X}=A D A^{\prime}
$$

Usando a matriz $A$, é possível construir um vetor $u(j t \times 1)$ tal que

$$
u_{j t}=A^{-1} \epsilon_{j t}
$$

Conforme já adiantado, os elementos de $u$ serão totalmente não correlacionados entre si:

$$
\begin{gathered}
E\left(u_{j t} u_{j t}^{\prime}\right)=\left[A^{-1}\right] E\left(\epsilon_{j t} \epsilon_{j t}^{\prime}\right)\left[A^{-1}\right]^{\prime} \\
E\left(u_{j t} u_{j t}^{\prime}\right)=\left[A^{-1}\right] \sum_{X}\left[A^{-1}\right]^{\prime} \\
E\left(u_{j t} u_{j t}^{\prime}\right)=D
\end{gathered}
$$

Sendo $D$ uma matriz diagonal, tem-se que os elementos $u_{j t}$ são mutuamente independentes, representando o elemento $(j t, j t)$ da matriz $D$ a variância do termo $u_{j t, j t}$. Multiplicando-se ambos os lados da Equação (A.1) por $A$, tem-se:

$$
A u_{j t}=\epsilon_{j t}
$$

Ou seja, a partir da decomposição (ou triangulação) da matriz $\left(\sum X\right)$, é possível transformar um vetor de choques independentes $(u)$ em um vetor de choques correlacionados $(\epsilon)$. A média dos choques gerados ainda é zero, uma vez que os vetores $(u)$ foram sorteados de uma distribuição com tal média. Para resolver o problema, basta somar os valores médios das variáveis (previsões) em cada data de interesse $t$ : 


$$
\left[\begin{array}{l}
x_{1,1} \\
\cdots \\
x_{1, T} \\
\cdots \\
x_{J, 1} \\
\cdots \\
x_{J, T}
\end{array}\right]=\left[\begin{array}{l}
\hat{x}_{1,1} \\
\ldots \\
\hat{x}_{1, T} \\
\ldots \\
\hat{x}_{J, 1} \\
\cdots \\
\hat{x}_{J, T}
\end{array}\right]+A\left[\begin{array}{l}
u_{1} \\
u_{2} \\
u_{3} \\
u_{4} \\
u_{5} \\
\cdots \\
u_{J T}
\end{array}\right]
$$

sendo a matriz A de tamanho $(j t, j t)$.

Adotando-se tal procedimento, tem-se, a cada sorteio, um vetor $(j t \times 1)$ de novos valores das variáveis de interesse $\left(X_{j}\right)$ em todas as datas de interesse $t$. Substituindo-se, a cada sorteio, esses valores nas equações que relacionam os fatores de riscos às contas do fluxo de caixa (conforme Equação 2) e essas na equação do fluxo de caixa (conforme Equação 1) tem-se, ao fim dos $n$ sorteios, a distribuição futura do fluxo de caixa. A partir dessa distribuição, é possível, por exemplo, calcular a probabilidade da empresa, em cada data de interesse, não dispor de recursos gerados pelas operações para honrar seus compromissos, o que ocorre quando seu fluxo operacional de caixa é negativo.

Uma última ressalva é pertinente: à medida que o número de fatores $j$ e o número de datas futuras de previsão $t$ aumentam, é difícil garantir que a matriz $\mathrm{X}$ será positiva definida, conforme requerido para a decomposição da matriz. $\mathrm{O}$ documento Riskmetric Group (1999), entretanto, sugere um método para garantir tal definitude. De acordo com o documento, uma matriz será positiva definida se, e somente se, todos os seus autovalores forem maiores que zero. Desta forma, estimando-se os autovalores da matriz $\sum_{X}$, caso haja algum autovalor menor ou igual que zero, sabe-se a priori que a matriz não pode ser decomposta. Para transformar os autovalores iguais ou menores que zero em autovalores positivos, o LongRun sugere uma pequena perturbação, dada por $z\left(I-\sum_{X}\right)$, sobre a matriz original:

$$
\sum_{X} \rightarrow \sum_{X}+z\left(I-\sum_{X}\right)=B
$$

onde:

$z$ é um escalar;

$I$ é a matriz identidade; e

$B$ é a matriz original perturbada, que pode ser decomposta se, após a perturbação, seus autovalores forem todos maiores que zero.

O valor de $z$, de acordo com o LongRun, é dado pelo Teorema de RayleighRitz:

$$
z \geq\left(\frac{-\lambda_{M}}{1-\lambda_{M}}\right)
$$

onde $\lambda_{M}$ é o valor do menor autovalor de $\sum_{X}$. 
Desse modo, o valor de $z$ que deve ser utilizado na perturbação é aquele levemente superior ao valor gerado pelo quociente do Teorema de Rayleigh-Ritz.

$\mathrm{O}$ procedimento acima descrito encontra-se completamente automatizado no software Crystal Ball. O Crystal Ball é um software de apoio à decisão que segue uma lógica muito simples, pautada na interligação de três tipos de células. A primeira delas é a célula de decisão, composta por variáveis que explicam a previsão, mas que estão sob controle do pesquisador (fixas). Cabe ressaltar que essas células não são requeridas obrigatoriamente em simulações, mas podem se tornar muito úteis na comparação e otimização de cenários alternativos. As variáveis de decisão são classificadas conforme sua peculiaridade em discretas ou contínuas.

Já as células de suposição encerram todas as variáveis que explicam a previsão e que possuem um grau elevado de incerteza quanto a seu comportamento, não estando sob o gerenciamento do pesquisador, ou seja, são variáveis estocásticas, com uma distribuição de probabilidades associada. A partir da opção "Fit" do software, para cada variável de suposição é escolhida uma distribuição de probabilidade a partir de uma série histórica de, no mínimo, quinze dados da série, fornecida como input. O software escolhe a melhor distribuição empregando testes do tipo Anderson-Darling, Qui-quadrado e Komolgorov-Smirnov.

A partir da escolha da distribuição, o software realiza sorteios aleatórios (em número igual a 1000) para cada célula de suposição. Tais sorteios são correlacionados entre as séries a partir da entrada no software da matriz de correlações entre elas, a ser fatorada por Cholesky.

Através da utilização da técnica de geração de números aleatórios (Simulação de Monte Carlo) para as variáveis de suposição, chega-se a 1000 valores prováveis para cada variável de suposição, que serão utilizados nas fórmulas constantes nas células de previsão, viabilizando a construção da distribuição de probabilidades da variável de interesse (variável de previsão).

A célula de previsão, por sua vez, é constituída por uma fórmula matemática que integra tanto as células de suposição quanto as células de decisão para obtenção de um valor médio estimado da variável de interesse e de sua respectiva distribuição de probabilidade. 